\title{
Guido Woldering \\ Über die Idee und das Wirkliche (Teil III)
}

https://doi.org/10.1515/asia-2018-0002

Zusammenfassung: Dieser Beitrag ist der abschliessende dritte Teil der Übersetzung der Summe von Ishibashi Ningetsus (石橋忍月, 1865-1926) poetologischen Überlegungen. Die literaturhistorische Bedeutung des Texts besteht in der Einführung eines weder regional noch historisch eingeschränkten, ausserdem auch alle Textsorten einschliessenden Konzepts der „Poesie“ (shi 詩), das sich klar vom klassischen Begriff der Schriftgelehrsamkeit (bungaku 文学) unterscheidet. Die japanische Literatur entwickelt sich damit $\mathrm{zu}$ einem vollwertigen Bestandteil eines autonomen Feldes „Kunst“. Eine weitere Leistung des Sō jitsu ron besteht in der Integration traditioneller japanischer und moderner europäischer theoretischer Ansätze. Das macht den Text zu einem Meilenstein auf dem Weg zu einer selbständigen japanischen wissenschaftlich-theoretischen Auseinandersetzung mit der eigenen Literatur.

Stichworte: Literaturtheorie, Intertextualität, Literaturbegriff, Textsorten

\section{Feilen und Schmieden ${ }^{1}$}

Ausdrücke wie „Feilen“ und „Schmieden“ werden von den Leuten häufig im Mund geführt. Doch klopft man deren Aussagen daraufhin ab, was denn die Hauptsache bei diesem Feilen und Schmieden sei, so sind sie verdutzt und haben nichts zu antworten. Insbesondere erkennt man nicht, dass die Notwendigkeit des Feilens und Schmiedens an der Poesie eben in jener einen Kunstfertigkeit ihre Rechtfertigung findet, die Idee und das Wirkliche aufeinander abzustimmen. ${ }^{2}$ Statt sich in

1 „Feilen“ für suikō 推敲 (,drücken oder schlagen“), bildlicher Ausdruck der Frage, welcher Ausdruck am besten passt); „Schmieden“ für tanren 鍛錬, bildlicher Ausdruck der intensiven Materialbearbeitung. Tanren ist eine weitere terminologische Leihgabe aus dem Kien shiwa (Kien-Ikeda 1972 [1771]: 185).

2 Logisch konsistenter müsste es wohl heissen „im Ergebnis der Kunstfertigkeit ihre Rechtfertigung findet“.

Originaltitel: Sō jitsu ron 想實論, von Ishibashi Ningetsu 石橋忍月

Guido Woldering, Frankfurt am Main, Germany. E-mail: guido.woldering@outlook.de 
seinem Text ganz dem Wirklichen zu verschreiben, möge man dieses lieber in einen hohen und weiten Entwurf überführen und so zu einem Text mit Kunstcharakter kommen. Statt sich in seinem Text von der Idee wegtragen zu lassen, möge man dies lieber unter Rückgriff auf niedere und erdnahe menschliche Gefühle ${ }^{3}$ in das Leben von Seele und Geist übertragen. ${ }^{4}$ Erst, wenn man dies erreicht hat, kann man Willkür und Leichtfertigkeit meiden, stattdessen ausgeglichen sein und in sich ruhen; dann ist es zu schaffen, dass die Sprache nicht aufdringlich ist, sondern sanft und harmonisch. Diejenigen, welche nur die Oberfläche der Begebenheiten

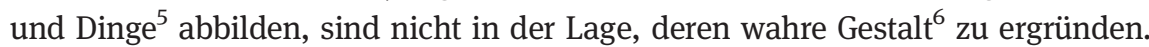
Dass die Mehrzahl der Dichtungen der Ming-Menschen ${ }^{7}$ nicht rein und ausgeglichen ${ }^{8}$ sind, liegt daran, dass sie sich in der Oberfläche verloren haben. Der Hauptinhalt dessen, was ich mit Feilen und Schmieden meine, besteht in der Tat aus nichts anderem als Idee und Wirklichem. Ich fordere, dass auch der Blickwinkel, von dem aus man die Poesie ${ }^{9}$ kritisiert und beurteilt, sich hauptsächlich auf die Geschicklichkeit beim Ausgleich zwischen Idee und Wirklichem fokussieren sollte. Die Kritiker der Gegenwart (besonders diejenigen, welche Romane kritisieren) sprechen nach einem kurzen Blick von Angenehmem, von Unausgereiftem und wollen ohne jedes Mass in Lob und Tadel die Zügel schiessen lassen. Wie gewaltig sind doch die Irrtümer, die daher rühren! Auf jenem Podium der Literaturkritik, ${ }^{10}$ selbst bei den Autoren der Shigarami zōshi, ${ }^{11}$ die als die hoch aufragende Kiefer im

3 „Menschliche Gefühle“ für ninjō 人情, was seit Tsubouchi Shōyōs Shōsetsu shinzui (1885/86) prägnant die Natur des Menschen bezeichnet.

4 Erneut bezieht Ishibashi sich auf Hahns Deutsche Poetik (1879).

5 „Begebenheiten und Dinge“ für jibutsu 事物, was hier als Abkürzung für die in Abschnitt 4 („Gebiet des Menschen und Gebiet der Poesie“ diskutierten Begriffe jinji 人事 („menschliche Begebenheiten“) und jinbutsu 人物 („Personen“) zu verstehen ist.

6 „Wahre Gestalt“ für shinsō 真相.

7 „Min-Menschen“ für Min-jin 明人, die chinesischen Dichter der Ming-Dynastie (1368-1644).

8 „Rein und ausgeglichen“ für junsui chūsei 純粋中正.

9 „Poesie“ für shigaku 詩学 („Gelehrsamkeit von der Dichtung“).

10 „Podium der Literaturkritik“ für bungaku no hyōron dan 文学の評論壇, eine dem Begriff bundan 文壇 (,literarisches Podium“) nachgebildete Bezeichnung. Auch diese Begriffsbildung, welche die Literaturkritik ebenso wie die Literatur in die Nähe darstellender Künste bringt, unterstützt die Vorstellung, dass literaturkritische (-theoretische) Texte als Kunstwerke anzusehen sind.

11 „Shigarami zōshi“柵草紙 (Titelvarianten: Bungaku hyōron Shigarami zōshi 文學評論しからみ 草紙, Shigarami zōshi しからみ草紙, Shigarami zōshi 志がらみ草紙): 1889 von Mori Ōgai 森鴎外 (1862-1922) gegründete Zeitschrift, die unter der Führung ihres Gründers bis August 1894 in insgesamt 53 Nummern literaturkritische Artikel der Gruppe Shinseisha 新声社 („Gesellschaft der neuen Stimme“, Akronym „S.S.S.“) veröffentlichte. Die wichtigsten Mitglieder dieser Gruppe waren Ochiai Naobumi 落合直文 (1861-1903), Koganei Kimiko 小金井喜美子 (1870-1956), Inoue Michiyasu 井上通泰 (1866-1941) und Miki Takeji 三木竹二 (1867-1908). Nummer 1 der 
Mischwald verehrt, ${ }^{12}$ als das edle Ross inmitten einer Schweineherde ${ }^{13}$ angesehen werden, deren Blick stets kühl bleibt und doch intensiv ist, ${ }^{14}$ begegnet man doch in Diskussionen von Theaterstücken, die einen grossen Teil deren Studien der Poesie ${ }^{15}$

Zeitschrift enthält 18 Texte, von denen sich 7 mit Fragen der Dramentexte beschäftigen (worauf Ishibashi im Folgenden durch die Bemerkung ,welche einen grossen Teil ihrer Studien der Poesie ausmachen“ Bezug nimmt).

12 „Hoch aufragende Kiefer“ für kyōshō 喬松, ursprünglich ein aus Namensbestandteilen von Wang Zijiao 王子喬 (jap. Ō Shikyō) und Chi Songzi 赤松子 (jap. Seki Shōshi) gebildetes Kompositum, das zwei als Heilige verehrte Figuren des chinesischen Altertums zu einer Allegorie der Unvergänglichkeit und der Unsterblichkeit zusammenfasst. Im Zusammenhang mit „Mischwald“ wird hier die wörtliche Bedeutung des Kompositums aktiviert, wodurch der Ausdruck ungleich weniger pathetisch wirkt als von seinem Schöpfer beabsichtigt. Diese „Demontage" bringt einen leicht ironischen Ton in den Text.

13 Der bildliche Ausdruck ist anderwärts nicht verifizierbar und wohl von Ishibashi spontan gebildet.

14 Den Anspruch des klaren Blickes zitiert Ishibashi aus dem programmatischen Vorwort „Shigarami zōshi no honryō wo ronzu 椢草紙の本領を論ず“ ([Über die Hauptaufgabe der Shigarami zōshi]) von Nummer 1 der Shigarami zōshi (Oktober 1889) (Mori 1889a). Mori Ōgai legt dort dar, dass angesichts der stürmischen Entwicklungen der zeitgenössischen japanischen Literatur kritische Betrachtungen notwendig seien, vielfach aber von traditionellen chinesischen und japanischen Auffassungen oder gar nur vom persönlichen Geschmack der Kritiker geprägt seien und demgegenüber Shigarami zōshi, klaren Massstäben der europäischen Ästhetik (shinbi gaku 審美学) folgend, mit ungetrübtem Auge Urteile fällen wolle (NKiBT 11: 358-360; OGZ 16: 25-28).

15 „Studien der Poesie“ für shigaku 詩学. In der Yomiuri shinbun vom 31. Okt. 1889 veröffentlichte ein Anonymus (Ichi Daigakusei 一大学生, „ein Universitätsstudent“) unter dem Titel „Shigarami zōshi no niki しがらみ草紙の二奇“ ([Zweierlei Sonderbarkeiten der Shigarami $z \bar{o} s h i])$ eine Kritik an der Shigarami zōshi und hält ihr vor: (1) Nur zwei Fünftel der japanischen Literatur seien Dramen, aber unter den 18 Beiträgen der Nr.1 haben 17 direkten Bezug zur dramatischen Literatur. Das sei unverhältnismässig. (2) Die Mehrheit der Beiträger seien Mediziner. Die lapidare Feststellung mag die Vorstellung implizieren, dass das Verfassen von Literatur idealerweise dem professionellen (keinem anderen Beruf nachgehenden) Autor überlassen bleiben sollte. Da dies aber nicht explizit gesagt wird, bleibt die Feststellung substanzlos. Zu dieser substanzlosen Feststellung nimmt Mori gar nicht erst Stellung. Dafür rechnet er dem „Universitätsstudenten“ in „Shigarami zōshi to geki to 柵草紙と劇と“ ([Shigarami zōshi, die dramatische Literatur und anderes] im November 1889 (Yomiuri shinbun; Mori 1889d) die Haltlosigkeit der von jener behaupteten Zweifünftel-Relation der Dramatik gegenüber anderen Textsorten vor. Dass Ishibashi hinter dem Pseudonym „Universitätsstudent“ steckt, liegt angesichts der für Ishibashi untypischen Substanzlosigkeit des Punktes (2) fern. Doch mag er sich durch Punkt (1) des „Universitätsstudenten“ angeregt gesehen haben, als er in Nr. 67 (1889) der Kokumin no tomo in seinem Beitrag „Bungaku hyōron Shigarami zōshi 文学評論柵草州紙“ ([Literaturkritiken Shigarami zōshi], KnT 5: 36-37; INZ 3: 95-96) kritisierte, dass Mori keine Rücksicht auf die Frage genommen habe, ob ein Text für eine Aufführung gedacht sei oder nicht. Im letzteren Fall handele es sich doch nicht um echte Dramen, sondern um „Literaturdramen“ (riteratsūru dorama 文園戯曲 [bun'en gikyoku]), so dass sie aus der Diskussion 
ausmachen, der Idee und dem Wirklichen mit einseitigem Blick! Um wieviel mehr ist dies bei anderen, minderen Kritikern der Fall! Bei ihnen reicht es von vorneherein nicht zu einer Teilnahme an der Diskussion über die Poesie. Seit alters war den Menschen, die den Hauptinhalt des Feilens und Schmiedens verstanden, bei der Disposition des Gesamtwerkes ${ }^{16}$ eine zwischen Idee und Wirklichem ausgleichende Gestaltung eine Selbstverständlichkeit, doch wenn sie dies auch bei Schriftwerken aus nur einem Ausdruck oder einer Zeile versuchen, fürchten sie, alleine schon an der Abbildung des Gegenstandes ${ }^{17} \mathrm{zu}$ verzweifeln. Wie sollte aber Poesie wie in Wang Mojies „Über die weite Marsch fliegt ein weisser Reiher, im tiefen Schatten der sommerlichen Bäume zwitschern goldene Buschsänger-Vögel“18 ihren

ausgeschlossen bleiben könnten. Mori entgegnet auf diesen Kritikpunkt in „Futatabi geki wo ronjite yo no hyōka ni kotau 再び劇を論じて世の評家に答ぶ “ ([Erneut das Drama erörternd antworte ich auf die zeitgenössischen Kritiker], Shigarami zōshi 3, Dez. 1889; Mori 1889c), er habe bei der Auswahl der behandelten Texte die formale Anlage der Texte in den Mittelpunkt gestellt. Im Übrigen seien Bedingungen für Bühnenaufführungen nach Zeit und Ort so verschieden, dass Unaufführbarkeit in einem Land zu einer Zeit den Text nicht zu einem „Literaturdrama“ machen könne. Diese Replik Ōgais ignoriert Ishibashi und impliziert hier erneut, dass durch den Einbezug von „Literaturdramen“ in Nummer 1 der Shigarami zōshi die Zahl künstlich hoch sei, geht also nicht auf Moris Argumente ein.

16 Das deutsche Wort „Disposition“ verschriftet Ishibashi hier nicht nach dem weiter oben besprochenen Muster (etwa mit jisupojishon 構造 [kōzō]), sondern mit einfachen Silbenzeichen zu jisupojishion ヂスポジション. Ishibashi zitiert das Wort „Disposition“ und sinngemäss das mit ihm verbundene Konzept wiederum aus Deutsche Poetik (1879) von Werner Hahn. Im vierten Abschnitt der Deutschen Poetik erklärt Hahn: „Das Dichtwerk soll (wie jedes Kunstwerk §. 14) ein Ganzes sein: ein in sich Geschlossenes; ein Gedankengang ohne Anknüpfung nach aussen, ohne Entlehnung von dorther und ohne Beziehung darauf; [..] Das Gesetz, nach dem ein Gewebe dieser Art geschaffen wird, nennt man „poetische Disposition“. Die poetische Disposition ist eine Richtung der Schönheit am Dichtwerk: und zwar diejenige, die das Aeussere des Dichtwerkes (d.h. die sprachliche Gestaltung) und ferner, die das Ganze des Dichtwerkes (d.i. den Aufbau zum Ganzen) betrifft. Sie stellt das harmonische Füreinander und Durcheinander aller Glieder dar (§. 17) und ist unmittelbar ein Theil des Dichtens; [..] Der Gegenstand der Poesie ersteht aus Gefühl und Gedanke des Menschen. Die Stufen seiner allmäligen Entwicklung, seiner Heranbildung zu einem Gegenstand der Poesie, sind innere Stufen des Seelen = und Geisteslebens. [..] „Poetisch bearbeiten“ heisst: nach dem Wesen der Schönheit bearbeiten. Und „poetische Disposition“ ist: Gedanken gestalten nach dem Wesen dieser letzteren, der Schönheit, so dass, wenn die Disposition sich verwirklicht, das Gedicht selbst entsteht.“ (Hahn 1879: 219-220).

17 „Abbildung des Gegenstandes“ für busshō 物象.

18 „Wang Mojie“ (sinojap. Ō Maketsu) 王摩詰: Wang Wei 王維 (ca. 699-759), chinesischer Dichter der Tang-Dynastie. Ishibashi zitiert hier (durch Inversionszeichen in kanbun umgeformt) die Verse 3 und 4 aus dem Gedicht „Jiyu Wangchuan-zhuang zuo 積雨輞川莊作“ ([Gedichtet in meinem Hause von Wangchuang nach einem langen Regen]). Das formenstreng in 8 reimenden Versen zu 7 Silben verfasste Gedicht (Typ „qiyanlü 七言律“) beschreibt die Idylle, in die sich der Erzähler vom Weg der politischen Karriere aus zurückgezogen hat. 
Sinn ${ }^{19}$ ausschliesslich in Reiher und Buschsänger-Vögel übertragen? Bei [Versen] wie „Sein Umriss bewegt sich so, als sei jemand um die Ecke herbeigekommen. Man wird gar eifersüchtig auf die Schmetterlinge, die wegen des schwingenden Duftes herbeikamen.“ von Gao Qingqiu ${ }^{20}$ oder „Auf herbstlichem Felde blühen in wilder Pracht von tausenderlei Farben die Blüten - eine Zeit, in der ich vielerlei bedenke“ von Tsurayuki ${ }^{21}$ bemerkt man, dass sich hinter der Anlage von stiller Einfachheit ${ }^{22}$ ein unausgesprochener emotionaler Nachklang verbirgt. [Das gilt] auch [für Texte] wie die folgenden: ${ }^{23}$,Vom Süden her kommt Wind auf/jene Sämlinge dort bekommen Flügel.“ (Tao Yuanming) ${ }^{24}$ „Als der alte Fischer sein Netz einholte,/waren darin mehr rote Ahornblätter als Fische.“ (Bussan) ${ }^{25}$ „Frühling ist es nun. Feiner Dunst um

In kakikudashi lauten die zitierten Verse: Mōmō suiden ni hakuro tobu, in'in kaboku ni kōri saezuru 漠々水田飛白鷺、陰々夏木囀黄死⿹ (Wang-Chen 1997 [759]-V: 444).

19 „Sinn“ für $i$ 意.

20 „Gao Qingqiu (sinojap. Kō Seikyū)“ 高青邱: der chinesische Dichter Gao Qi 高啓 (13361374). Ishibashi zitiert hier (durch Inversionszeichen in kanbun umgeformt) aus dessen Gedicht „Linjia taohua 鄰家桃花“ ([Die Pfirsichblüten des Nachbarhauses]). Gao beschreibt einen Pfirsichbaum am benachbarten, östlich gelegenen Haus, der sich wegen des niedrigen Zaunes ohne Hemmungen in den Garten des Betrachters hinüberzuneigen und diesen aufreizend anzuschauen scheint. Der Nebentrakt des benachbarten Hauses sei fest verschlossen, es sei niemand zu sehen, weswegen die Pfirsichblüten ganz dem Genuss des lyrischen Ichs überlassen seien. An diese Darstellung schliesst sich die im Folgenden in kakikudashi zitierte Passage an: Kage ugoite hito no oru wo utagai, kō yuraide chō no tazunuru wo netamu 影動擬人折、香摇妒蝶尋. An die zitierte Passage anschliessend schildert Gao Qingqiu, dass angenehmer Frühlingswind bisweilen Pfirsichblütenblätter $\mathrm{zu}$ ihm wehe und diese seinen Ärmel wie zur Erwiderung der Zuneigung zu streifen schienen (ZKKTS 3: 515).

21 „Tsurayuki“ 貫之: Ki no Tsurayuki 紀貫之 (ca. 868 - ca. 945). Ishibashi zitiert (in einer orthographischen Variante) das waka Nr. 583 aus dem Kokin wakashū 古今和歌集 (Sammlung japanischer Lieder aus alter und neuer Zeit, ca. 914), das im Original wie folgt lautet: Aki no no ni / midarete sakeru / hana no iro no/ chigusa ni mono wo / omou koro kana あきののみだれてさける 花の色のちぐさに物を思ふころかな (NKBT 8: 218). Übersetzung: „For me these are days / when my musings are as varied / as colors of flowers / blooming in mingled beauty / all through an autumn meadow.“ (McCullough 1985: 340).

22 „Stille Einfachheit“ für heitan 平淡 (,flach und seicht“).

23 Im Original sind die folgenden vier Zitate in einen erst nach den Gedichten endenen Satz integriert. Der Übersichtlichkeit halber ergänze ich hier ein im Original nicht enthaltenes Prädikat.

24 Tao Yuanming (sinojap. Tō Enmei) 陶淵明 ist der von Ishibashi in Klammern gegebene Dichtername des Chinesen Tao Qian 陶潜 (365-427). Ishibashi zitiert hier in japonisierter Form das Gedicht Shiyun 時運 ([Zeitläufte]), in dem Tao Qian seine Eindrücke bei einem morgendlichen Spaziergang schildert. In japonisierter Form lautet das Original: Minami yori kaze ari, ka no shinbyō ni tsubasa 有風自南、翼彼新苗. „Suddenly a wind comes from the south / And gives wings to the new sprouts.“ (Tao/Chang 1954 [427]: 12).

25 „Bussan“ 仏山 meint Bussan dō 仏山堂, den Dichternamen des Murakami Kō 村上剛 (1810-1879). Das Gedicht chinesischen Stils (kanshi 漢詩), aus dem Ishibashi hier zitiert, ist 
den namenlosen Berg.“ (Bashō) ${ }^{26}$ „Wenn man Fetzen von dunkelvioletten oder traubenvioletten Stoffen, die man in ein Heft eingelegt hatte, wiedergefunden hat. Oder auch wenn man an einem Tage, an dem es ununterbrochen regnet und man Mussestunden hat, den Brief eines Menschen, für den man einst etwas empfunden hat, sucht und wiederentdeckt." (Sei Shōnagon) ${ }^{27}$ Wären diese nicht aus dem Pinsel von Menschen geflossen, die ein vom Himmel gegebenes poetisches Genie in sich tragen oder dem tiefsten Geheimnis der Poesie auf den Grund gegangen sind, so hätten sie nicht als Verse mit einem derartigen emotionalen Nachklang, eleganter Melodie und Bildhaftigkeit ${ }^{28}$ zutagetreten können. Letztendlich: Wie sollte man das, was ich emotionalen Nachklang nenne, was ich elegante Melodie nenne, was ich Bildhaftigkeit nenne, erreichen, wenn man das Feilen und Schmieden beiseiteliesse? Um zu erhärten, was ich gesagt habe, will ich im Folgenden eine grosse Zahl von Beispielen (zumeist aus Romanen) ${ }^{29}$ anführen. Dabei handelt es sich allerdings nur um sehr kurze Passagen und ich habe sie wahrlich nicht von ihrer Situierung in der Gesamtanlage her betrachtet. Nein, die Kunstfertigkeit der Dichtung bei der Gestaltung des Gesamtwerkes mit einzubeziehen, würde mir der zur Verfügung stehende Platz schliesslich nicht verstatten.

enthalten in Murakamis Sammlung Bussan dō shishō 仏山堂詩鈔 („Auszüge aus den Gedichten des Meisters Bussan“, 1852) und trägt den Titel „Tochū shoken 途中所見“ ([Was unterwegs zu sehen war]; Band 1, Seite 2a). Das Gedicht schildert die Szene eines herbstlich kalten Abends an einem Teich, auf dem ein Fischer im letzten Schein der Abendsonne sein Netz aus dem stillen Wasser einholt. Die zitierte Passage lautet: Gyoō ami wo aguru tokoro, kōyō uo yori ōshi 魚翁擧網處、紅葉多於魚 (Murakami-Fujikawa 1989 [1852]: 420).

26 „Bashō“: der Haiku-Dichter Matsuo Bashō 松尾芭蕉 (1644-1694). Ishibashi zitiert hier ein haiku-Gedicht, das Bashō in verschiedene Sammlungen integriert hat, unter anderem in das Reisetagebuch Nozarashi kikō 野ざらし紀行 (Exposure in the fields, 1687): Haru nare ya / na mo naki yama no / usu-gasumi 春なれや名もなき山の薄霞. Die 1687 fertiggestellte Version ist die vierte Überarbeitung des ersten Manuskriptes. NKBT 46 gibt an, dass in früheren Versionen statt usu-gasumi (,feiner Dunst“) asa-gasumi („morgendlicher Dunst“) gestanden habe, zitiert aber unverständlicherweise dieses haiku nicht in der von Bashō offensichtlich beabsichtigten Endversion mit usu-gasumi, sondern mit der von Bashō verworfenen Variante mit asa-gasumi (vgl. NKBT 46: 26).

27 Zitat aus Abschnitt 30 („Suginishi kata omoishiki mono“, „Dinge aus vergangenen Zeiten, die wehmütige Erinnerungen wecken“) des Makura no sōshi (um 1000) von Sei Shōnagon (NKBT 19: 72). In der Übersetzung: „Wenn man tiefblau und zartlila gefärbte Stoffschnipfel in einem Notizbuch eingepresst findet. Wenn man an einem regnerischen Tag voll Musse den Brief eines Menschen aufstöbert, dem man damals seine Gefühle geschenkt hatte.“ (Sei/Arnold-Kanamori 2001 [um 1000]: 96-97).

28 „Elegante Melodie“ für fūin 風韻, „Bildhaftigkeit“ für gūi 寓意.

29 „Romane“ für shōsetsu 小説. 
Zwar hat man in die Blumenbank mit Bedacht Erde gegeben und die Blumen darin eingepflanzt, doch da man sie von der vertrauten Erde von Yoshino getrennt und in nicht vertraute Erde aus der Hauptstadt gepflanzt hat, sind sie alsbald verdorrt, und ihre Farbe hat sich in Violett ohne Frische verwandelt, so dass sie schliesslich der Missachtung anheimfielen und man sie im grossen Kessel verbrennen liess, was sicherlich auch die Blumen traurig und bedauernswert empfunden haben werden. (Keisei Uta Shamisen) ${ }^{30}$

\section{Dazu sagt die Kritik ${ }^{31}$ : [Der Text] tritt vom Wirklichen her in die Idee ein, erweckt Unbelebtes mit Leben und lässt Niedriges und Erdnahes in überlegen Schönes übergehen.}

Er erfreute sich daran, vom Reiswein so betrunken zu werden, dass er wie ein Orang-Utan mit den Armen kraulte, und seine Füsse flatterten wie ein Wandbehang [im Winde].“ $\left(\right.$ Saikaku okimiyage) ${ }^{32}$ „Sein Sohn hatte, bis er achtundzwanzig wurde, noch nicht einmal seinen Fuss auf die Matte eines Bordelles gesetzt, und noch heute kommt er mit jenem seidenen Lendenschurze aus, welchen man ihm im Alter von sieben Jahren für das Erste Schreiben $^{33}$ gekauft hatte. (desgleichen) ${ }^{34}$

30 Zitat aus Band 3 des bereits erwähnten Keisei uta Shamisen けいせい歌三味線 ([Lieder eines Freudenmädchens zur Laute], 1732) von Ejima Kiseki. In dieser Passage vergleicht die aus der Provinz Mikuni in die Hauptstadt Edo „verpflanzte“ Prostituierte ihr Schicksal mit dem aus Yoshino stammenden, in eine Blumenbank verpflanzten Kirschbäumchen (KNBT 5: 475). „Yoshino“ 吉野 ist ein Gebiet bei Nara, berühmt für die Pracht seiner Kirschbäume.

31 „Dazu sagt die Kritik“ für Hyō iwaku 評曰, eine Formulierung, die in ihrer unpersönlichen Art Objektivität beansprucht, aber Ishibashi selbst meint.

32 „Saikaku okimiyage“ 西鶴置土産 (Saikaku’s Parting Gift): 1693 gedruckter Text des Ihara Saikaku 井原西鶴 (1642-1693). Kern des Textes sind 15 Geschichten um der Liebe verfallene Männer. Ishibashi zitiert hier aus Abschnitt 2 in Heft 3 (NMZ 2: 690), in dem es um die Enteignung des lasterhaften Vaters durch seinen sittenstrengen Sohn geht. In der Übersetzung von Robert Leutner: „He likes to get so drunk that his legs wobble like a hanging scroll flapping in the wind and his arms flail around like a drunken orangutan swimming a crawl stroke.“ (Ihara/Leutner 1975 [1693]: 385-386). Leutner weist auf die sprachliche Komplexität der Passage hin. Zum einen zitiert Saikaku hier aus dem Nō-Theaterstück Shōjō 猩々 („Orang-Utan“, Verf. angeblich Zeami Motokiyo, 1363-1443) die Vorstellung des Orangutans als Bild der Volltrunkenheit. Zum anderen ist im Original das Wort für „Füsse“ (ashimoto) auch auf das untere Ende des Wandbehanges zu beziehen. Und schliesslich lässt sich die Phrase „Er erfreut sich daran“ auch auf den Wandbehang beziehen.

33 „Erstes Schreiben“ für kakizome 書初め, eine Zeremonie der terakoya-Schulen (Grundschulen für Kinder der Edo-Zeit), bei der die Schüler am 5. Tag des neuen Jahres in der Schule ihre Schreibfertigkeiten in Wiederholungsübungen unter Beweis stellen mussten. Es war Brauch, dass Verwandte dem Schüler zu dieser Zeremonie einen neuen Lendenschurz (fundoshi) schenkten.

34 Weiteres, diesmal allerdings inakkurates Zitat aus Saikaku okimiyage (Saikaku's Parting Gift), Abschnitt 3-2 (NMZ 2: 690). In Ishibashis Zitat fehlt die von Robert Leutner korrekt übertragene Erwähnung der Tante im Stadtteil Nakabayashi: „His son, though, had never trodden the mats of a brothel, even though he was twenty-eight. When the son was seven, an aunt in 
Dazu sagt die Kritik: Diese beiden Abschnitte treten von der Idee aus in das Wirkliche ein und geben auf geschickte Weise eine Vorstellung ${ }^{35}$ von gesamten Lebenswandel, den Vater und Sohn pflegen.

Sie zählte sechzehn Jahre, ${ }^{36}$ und als Kirschblüte wäre sie die Hochblüte von Ueno, als Mond so rein wie die Umrisse des Mondes über dem Sumida-Flusse gewesen. ${ }^{37}$ Eine solch schöne Frau gibt es eigentlich gar nicht! Die Zeit aber war eine andere als die jenes Narihira mit seinem Vogel aus der Hauptstadt - wie bedauerlich, dass man sie ihm nicht zeigen konnte! $!^{38}$ (Auslassung) ${ }^{39}$ Sie freute sich. ${ }^{40}$ Sie ergriff seine Hand und machte sich erbötig, ihm aus dieser schwierigen Lage zu helfen. Der junge Mann hielt völlig selbstvergessen ihre Hand fest, und sie konnten sich nicht voneinander lösen. Der Blick der Mutter aber war abweisend, so dass sie voneinander Abschied nehmen mussten, ob sie nun

Nakabayashi bought him his first loin cloth, a silk one, and even now he's still making do with it.“ (Ihara/Leutner 1975 [1693]: 386).

35 „Eine Idee geben“ für suisō seshimu 推想せしむ. Darin ist das Wort sō 想, mit dem Ishibashi im Rahmen seiner Arbeit die „Idee“ bezeichnet. Aus idiomatischen Gründen im zweiten Teil des Satzes in „Vorstellung“ übersetzt.

36 Diesen und den nach einer Auslassung folgenden Abschnitt zitiert Ishibashi aus Kōshoku gonin onna 好色五人女 ([Fünf der Lust ergebene Frauen], 1686), Erzählungen über Liebesbeziehungen zwischen Frauen und Männern von Ihara Saikaku. Beide zitierten Abschnitte sind Kapitel 1 des 4. Bandes entnommen (NKBT 47: 283 f.). Saikaku erzählt darin von der Schönheit der Tochter eines Gemüsehändlers und der aufkeimenden, von der Mutter argwöhnisch beobachteten Liebe zu einem jungen Samurai, mit dem sie auf der Flucht vor einer Brandkatastrophe zufällig in einem Tempel zusammengetroffen ist.

37 In der Edo-Zeit galt die Gegend von Ueno als schönster Ort für die Zeremonie der Kirschblütenschau (hanami), die Ufer des Sumida-Flusses als der schönste Ort für die Zeremonie der Mondschau (tsukimi).

38 Saikaku spielt hier auf ein im Abschnitt 9 des Ise monogatari 伊勢物語 (Geschichten aus Ise, 10. Jhdt., Ariwara no Narihira 在原業平 zugeschrieben) enthaltenes Gedicht an, in dem ein junger Mann auf einem Schiff fern der Hauptstadt einen „Hauptstadt-Vogel“ sieht und daraufhin, von Sehnsucht nach der in der Hauptstadt verbliebenen Frau überwältigt, dichtet: Na ni shi owaba / iza koto towamu / miyako-dori / Waga omou hito wa ari ya nashi ya 名にし負はばいい ざ事とはむ宮こ鳥わが思ふひとはありやなしや (NKBT 9: 117), zu Deutsch „Wenn du zu recht so / heisst, will ich etwas fragen / du Hauptstadtvogel: / Ist sie, die ich so liebe/ noch am Leben oder nicht?“ (Naumann 1973: 78). Es heisst im Weiteren, dass der junge Mann mit seinem Gedicht alle auf dem Schiff zu Tränen gerührt habe.

39 Nach der kleinen (durch „chūryaku 中略“ als solche gekennzeichneten) Auslassung zitiert Ishibashi die Szene, in welcher das Mädchen und der Samurai sich ineinander verlieben. Die Mutter des Mädchens will dem Samurai beim Herausziehen eines Splitters aus der einen Hand helfen, muss aber wegen ihrer schwachen Augen die Tochter dazubitten.

40 Ishibashis Zitat beginnt mit dem finalen Prädikat des vorigen Satzes (ureshi, „Sie freute sich“, MBgZ 23: 288). Das Prädikat kennzeichnet die Freude der Tochter darüber, dass sie zur Hilfe von der Mutter herangerufen wird und sich so dem attraktiven jungen Mann nähern kann. Der junge Samurai ergreift die Hand des der Mutter assistierenden Mädchens - der Moment, in dem der Funke überspringt. 
wollten oder nicht. Sie entfernte sich, nahm aber ganz absichtlich die Pinzette mit. Dann ging sie ihm nach, um sie zurückzugeben, und als sie nun ihrerseits fest seine Hand drückte, ... (Saikaku Gonin onna). ${ }^{41}$

Dazu sagt die Kritik: Ein Werk allerhöchster Harmonie von Idee und Wirklichem. Jedes einzelne Wort ist wie ein Kristall, wie reinste Tautropfen. Es lässt uns vermuten, dass wohl die göttliche Seele der Muse in jedem Körnchen und in jedem Tropfen tanzen. ${ }^{42}$

Mit diesem Besuch hat es eine Bewandtnis, spürt Akoya in ihrem Herzen, doch äusserlich ist sie um prächtige Bewirtung bemüht. ,Diese wechselvolle Welt ist wirklich seltsam! Selbst wenn man sich in einem derart einsam gelegenen Viertel der Lustbarkeiten einrichtet, bleibt man noch bis in entlegene Provinzen nicht verborgen und es heisst, man wolle Akoya sehen, wolle sie rufen. Dass mir, die ihren Platz in dieser Welt des Leides eingenommen hat, derartige Aufmerksamkeit zuteilwird, übersteigt in beschämender Weise alle Wünsche und Erwartungen. Alles sollte man dafür eigentlich beiseiteschieben und eilig zurückkehren, doch zu meinem Leidwesen ging es nicht nach meinem Herzen, und ich konnte nicht aufstehen und meine auswärtigen Gäste verlassen. Nach umständlichsten Erklärungen bin ich nun endlich [für Sie da]. Mögen Sie mir verzeihen, dass ich so spät bin!' sprach sie, zündete eine Tabakspfeife an und reichte sie dar. (Dan no ura Kabuto gunki) ${ }^{43}$

41 In der Übersetzung von William de Bary sind Teile der Passagen umarrangiert und sehr frei übersetzt: „[..] fifteen years old, as beautiful as the blossoms of Ueno, as delicately radiant as the moon shining on Sumidagawa. Indeed, it was unfortunate that she had not appeared in the time of Narihira, for the miyako bird could not have found a lady so fair. In her own time Oshichi was the woman of almost every man's desire. [..] At last, to her delight, Mother suggested that Oshichi try. Taking the tweezers, she soon delivered him from pain, but by this time the young man's thoughts were entirely of his deliverer and not at all of the splinter. Impulsively he squeezed her hand tight. He did not want Oshichi to go any more than she herself did, but Mother was watching, and, like it or not, they had to part. Oshichi started away, intentionally keeping the tweezers in her hand. „Oh, I must take these back,“ she said to her mother a moment later, and following after the young man, she squeezed his hand as he had hers, [..].“ (De Bary 1956 [1686]: 160-163).

42 „Muse“ für mūze ムーゼ, womit Ishibashi den deutschen Namen der neun Schutzgöttinen der Künste und der Wissenschaften aus der griechischen Mythologie (griech. musai) zitiert.

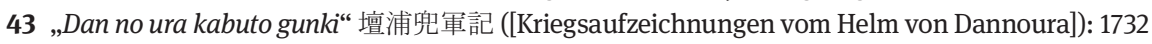
uraufgeführtes jōruri-Puppentheaterstück von Bunkōdō 文耕堂 (Matsuda Kazuyoshi 松田和吉, fl. 1730) und Hasegawa Senshi 長谷川千四 (1689-1733). Ishibashi zitiert aus dem zweiten Aufzug. Es geht um die für ihre Schönheit weitbekannte Dirne Akoya. Unter dem Vorwand, diese berühmte Schönheit kennenlernen zu wollen, kommt der Beamte Michinatsu mit seiner Tochter in das Freudenhaus, in dem Akoya angestellt ist. Das eigentliche Ziel seines Besuches ist es, mithilfe seiner Tochter die Dirne auszufragen und den Aufenthaltsort ihres Geliebten Kagekiyo, der als Verbrecher gesucht wird, zu erfahren. In der hier zitierten Szene kommt Akoya von einem auswärtigen Kundenbesuch wieder und findet Michinatsu und dessen Tochter wartend vor (NKBZ 45: 394-395). 
Dazu sagt die Kritik: Die zwei Wörter „liebenswert“ und „liebreizend“ sind leicht ausgesprochen, aber schwierig zu erklären. Dies Schriftwerk ist ohne Einschränkungen dazu angetan, diese Schwierigkeit zu demonstrieren. Durch die sprachliche Atmosphäre dieses Abschnittes teilen sich Wesen und Erscheinung mit. Das ist die besondere Fertigkeit dieses Autors.

,Auch im Schatten der Bäume erblühen die Blumen, und auch das Wasser, welches sich zwischen den Felsen sammelt, klart auf. ${ }^{44}$ Aber in Gedanken an die Welt, in der ich lebe, möchte ich mich dreingeben', so hatte sie endlich einige wenige Worte hervorgebracht. (Shinrei yaguchi). ${ }^{45}$

Im Folgenden will ich noch einmal meinen Blick umlenken und $\mathrm{zu}$ den vorigen Beispielen noch zwei oder drei aus literarischen Meisterwerken der Gegenwart anführen. ${ }^{46}$

Ich glaubte, dass aus dem Inneren ein Gespenst an mir zieht, schrie vor Schreck ein ,Aah!' heraus, glitt gleich darauf auf den Samenkörnern des Biwa-Baums aus - ja, im Juni vergangenen Jahres war's, dass ich einmal derart den Verstand verloren habe. (Kōson, Kakeochi no kakeochi) ${ }^{47}$

Dazu sagt die Kritik: Hier wird das Gestalthafte abgebildet, man schliesst auf das Gestaltlose. ${ }^{48}$

44 Zwei bildliche Ausdrücke dafür, dass auch ein Mädchen (verbildlicht durch „Blüte“ und „Wasser“) vom einsamen Lande (verbildlicht durch „Schatten“ und „Felsspalte“) die Dinge der Liebe begreift (verbildlicht durch „erblühen“ und „aufklaren“), wenn nur das richtige Alter dafür erreicht ist.

45 „Shinrei yaguchi“: Kurztitel des jōruri-Puppentheaterstückes Shinrei yaguchi no watashi 神霊矢口渡 ([Göttlicher Geist bei der Fähre von Yaguchi], 1770) von Hiraga Gennai 平賀源内 (1728-1779). Die hier von Ishibashi zitierte Passage findet sich im vierten Aufzug (NKBT 55: 387). O-Fune, die Tochter des Wächters an der Fähre, hat sich in Yoshimine verliebt, doch ist dieser zusammen mit seiner Geliebten auf der Flucht. O-Fune kann unter den gegebenen Umständen (,in Gedanken an die Welt, in der sie lebt“) ihre Liebe nur dadurch in die Tat umsetzen, dass sie sich selbst zurücknimmt (,dreingibt“) und den beiden zur Flucht verhilft. 46 Bemerkenswerterweise kommentiert Ishibashi die zitierte Passage aus Shinrei yaguchi no watashi im Gegensatz zur zuvor zitierten Passagen nicht.

47 „Kōson“: Aeba Kōson. Ob das Erscheinen von dessen Erzählung Kakeochi no kakeochi 駆落の 駆落 ([Weglaufen vor dem Weglaufen]) in der Sammlung Shōsetsu muratake im September 1889 die Erstveröffentlichung ist, ist nicht zweifelsfrei zu klären (MBgZ 26: 434). Der moderne Nachdruck in MBgZ 26 (S. 108-114) basiert jedenfalls auf dieser Version. Die Erzählung handelt vom „Durchbrennen“ einer jungen Frau und ihres Geliebten. Unmittelbar vor der hier zitierten Passage aus Abschnitt 6 schildert die Protagonistin zur Illustration ihres ängstlichen Wesens, wie sie einmal nachts das für sie zu grosse Gewand des Angesprochenen anlegte, um zum Wasserlassen den Abort aufzusuchen, und mit dem Gewand an der Aborttüre hängenblieb (MBgZ 26: 113).

48 „Gestalthaftes“ für ukei 有形, „Gestaltloses“ für mukei 無形. 
Obgleich es doch mit mir nichts zu tun hat/Warum entströmen mir doch derart die Tränen?/Du zertretene Rose!/Wahrlich, in dieser dahintreibenden Welt ist dies Schicksal gewöhnlich! (S.S.S., „Hana sōbi““) 49

In tiefer Nacht bei hellem Mondenschein auf den Wellen/fährt ein Schiff weit hinaus./Man kann von Zeit zu Zeit ein Lied hören./Es rudert dort wohl einer, der sehnsuchtsvolle Gedanken hegt. (desgleichen, „Fue no oto“) ${ }^{50}$

49 „S.S.S.“: Akronym der Dichtergesellschaft Shinsei sha. Das hier zitierte Gedicht „Hana sōbi“花薔 薇 ([Die Rose]) ist die Übersetzung der 9. Strophe des Gedichtes „Die Rose im Staub“ (1868) des evangelischen Theologen und Kirchenlieddichters Karl Gerok (1815-1890). Das Gedicht schildert eine am Boden liegende Rose, welche, „eines losen Buben Raub“ geworden, ihren Wert verloren hat. Die Kommentatoren Kanda Takao 神田孝夫 und Kobori Kei’ichirō 小堀桂一郎 vermuten, dass Inoue Michiyasu 井上通泰 (1866-1941) das Original nach Anregung durch Mori Ōgai, welcher der Vorlage den handschriftlichen Kommentar „Prostitution“ beigegeben hat, übersetzte (NKiBT 52: 130-131, Anm. 6; NKiBT 52: 422). „Hana sōbi“ ist Teil der aus 17 Lyrikübersetzungen bestehenden Sammlung Omokage 於母影, die im August 1889 in der Kokumin no tomo 国民之友 als Veröffentlichung der „S.S. S.“ erschien. Meine Rückübersetzung folgt dem modernen Nachdruck in Ishibashi-Kawazoe 1972 [1889] (Shinseisha-Yoshida 1971 [1889], NKiBT 52: 105-167), der den Titel wie Ishibashi, das Gedicht aber komplett in hiragana (Silbenschrift) wie folgt zitiert: Wa ga ue ni shi mo aranaku ni / Nado kaku otsuru nami zo mo / Fumikudakareshi hanasōbi / Yo wa nare nomi no ukiyo ka wa. Es fällt auf, dass Inoue das im Original nicht versprachlichte Erdendasein mit dem Ausdruck ukiyo うきよ bezeichnet. In der ursprünglichen (aus dem Buddhismus kommenden) Schreibung ukiyo 憂世 (,traurige Welt“, „Jammertal“) wird damit das Erdendasein als leidvoll beschrieben, mit der während der Edo-Zeit üblichen Schreibung ukiyo 浮世 (,fliessende, vergängliche Welt“) ist die Idealvorstellung des gerade wegen seiner Vergänglichkeit zu geniessenden Erdendaseins verbunden und wurde häufig zur Bezeichnung der Welt der Freudenviertel verwendet. Inoue lässt durch die in reiner Silbenschrift mehrdeutige Schreibung sowohl das Bild vom Jammertal als auch das Bild vom Freudenviertel anklingen. Im Übrigen verändert er an zwei Stellen durch Zusatz von kanji die Orthographie (hanasōbi 花そうび und Yo wa 世八), wohl um den Text durch Aufzeigen von Wortgrenzen leichter lesbar zu machen. Ausserdem bricht Ishibashi an den Versenden nicht um, sondern markiert sie durch einen Punkt (maru 。) (MBgZ 23: 288), die in meiner Übersetzung hier und analog im Folgenden durch Schrägstriche (/) gekennzeichnet werden. Die in Übersetzung zitierte Stelle lautet in Karl Geroks Original: „Und warum bei deinem Loose / Mir das Herz vor Wehmut bricht: / Du in Staub getretne Rose, / Ach! du bist die einzge nicht!“ (Gerok 1885: 62-63). Dass die gebrochene Rose hier bildlich für „schöne junge Frau, welcher die sexuelle Jungfräulichkeit geraubt wurde“ steht, liegt in Zusammenhang unter anderem mit dem erwähnten „losen Buben“ nahe. Ob aber Gerok (wie Mori Ōgai offensichtlich annahm) hier speziell die Prostitution oder den ausserehelichen Geschlechtsverkehr allgemein geisselt, ergibt sich aus dem Originalgedicht nicht.

50 „Fue no oto 笛の音“ ([Der Klang der Flöte]) ist der Titel der wohl von Ochiai Naobumi stammenden Teilübersetzung des Versepos’ Der Trompeter von Säkkingen: Ein Sang vom Oberrhein (1854) von Josef Victor von Scheffel (1826-1886). Die Teilübersetzung erschien erstmals 1889 in Omokage. Aus der Übersetzung der dritten Stophe des zweiten „Liedes“ in Abschnitt 14 („Das Büchlein der Lieder“) des Versepos’ zitiert Ishibashi eine Passage wie folgt: „Yo fukaki nami ni tsuki saete / okibe wo tōku fune zo yuku / oriori uta no kikoyuru wa / mono omou hito ya koguramu.“夜ふかき波に月さ えて・おきべをとほく舟ぞゆく・をり〉うたのきこゆるわ・もの思ふ人こぐならむ (NKiBT 52: 
Dazu sagt die Kritik: Weil er nicht an die Vergangenheit denkt, richten sich seine Gedanken wohl an seine Heimat oder an eine Geliebte. Seit alters sind mit dem Mondlichte Empfindung und Sehnsucht verbunden. Von meinem Lehrer, dem ehrenwerten Son'an, gibt es folgendes Gedicht:

In der Hauptstadt Saiten- und Blasinstrumente, ${ }^{51}$ auf dem Meere das Schiff./Einige sind in der Stimmung zum Dichten, einige spassen./Entschwundene Zeiten regnen weithin herab aus den Wolken./Das Mondlicht strahlt lange auf die alte Heimat im Herbst. ${ }^{52}$

Ihr bringt mir warmes Wasser zum Händewaschen mit auf die Veranda, fasert Weidenholzsplitter ein wenig auf und bringt sie mir zusammen mit einem Salztellerchen auf einem Lacktablett $^{53}$ - bis in die kleinsten Dinge hinein [geht es bei Euch]! Und dazu umsorgt Ihr andere mit den Worten ,Ach, wie dauert es mich, dass ich mit meiner schlechten Angewohnheit, früh aufzustehen, dich dazu bringe, ebenfalls früh aufzustehen und ungerührt dazu zwinge, in dem noch kalten Morgenwind mühselig das Gewand glattzustreichen.

125-126; Punkte ersetzen den Zeilenwechsel des Originals). In seinem Zitat ersetzt Ishibashi die originalen Zeilenumbrüche durch Punkte, schreibt die im Original in hiragana gesetzten Wörter okibe 沖邊, uta 歌 und omou 思予 mit kanji, schreibt das originale fune 舟 in der Variante fune 船 und setzt bei mono omou hito die im Original nicht vorhandene Partikel ya dazu. Auffälliger als diese äusserliche Entstellung ist indes, dass Ishibashi zu den erheblichen Freiheiten, die sich der japanische Übersetzer leistet, keine Stellung bezieht. Das deutsche Original lautet nämlich wie folgt: „Auf dunkeln Wasserpfaden / Tanzt spielend leicht ein Schiff, / Es klingt ein fremdes Singen / Heran zum Felsenriff.“ (Scheffel 1870 [1854]: 242-243). Die sich im Original anschliessende letzte Strophe lautet: „“Oh wenn ich doch am Rheine / Bei meiner Liebsten wär’ / O Heimath, alte Heimath, / Wie machst das Herz du schwer.” (Scheffel 1870 [1854]: 243).

51 „Saiten- und Blasinstrumente“ für shichiku 絲竹 („Faden und Bambus“).

52 „Son'an 巽庵“ ist eine nicht verifizierbare Variante von Son'an 巽荓, des Dichterpseudonyms des Sinologen Ezaki Wataru 江碕済 (1845-1926). Ezaki unterrichtete in Kurume (Kyūshū) an der Kuroki juku 黒木塾, einer Privatschule für „chinesische Studien“ (kangaku 漢学), in der Ishibashi ab 1879 konfuzianische Klassiker und chinesische Dichtkunst studierte (Chiba 2006: 34-40). Das nicht verifizierbare, von Ishibashi ohne Titel und Inversionszeichen zitierte Gedicht besteht aus 4 Versen zu 7 Silben. Die kakikudashi-Fassung lautet: Tomon wa shichiku, kaimon wa fune / ikusama shijō, ikusama asobi / ōji bōbō to kumo yori chiru / gekkō kosan no aki ni eishō $s u$ 都門絲竹海門舟、幾様詩情幾様遊、往時茫々與雲散、月光永照故山秋 (MBgZ 23: 288). Durch drei Sachverhalte entsteht hier eine systematische Inkonsistenz: (a) Zum einen kommentiert Ishibashi nicht einen bisher eigens zur Kommentierung zitierten Text (die Übersetzung des Gerok-Gedichtes), (b) zum anderen verlässt Ishibashi hier die sprachanalytische Ebene und interpretiert den motivischen Gehalt des zweiten Gedichtes, (c) und schliesslich stellt er zur Erläuterung seiner inhaltlichen Interpretation ohne Formulierung einer entsprechenden Aussage ein zweites Gedicht (das Gedicht seines Lehrers Ezaki) dazu.

53 Hier wird geschildert, wie freundlich der angesprochene Mann der Frau bei der Vorbereitung der Morgentoilette zur Hand geht. Traditionell faserte man das Ende eines Zahnstochers auf und tauchte es in Salz. Die auf diese Art gesalzene Zahnbürste verwendete man zur Zahnreinigung. 
Wahrlich, nicht im mindesten ist es schade darum, Euch die dem Menschen gegebenen fünfzig Jahre zu schenken! (Rohan, Fūryū butsu). ${ }^{54}$

\section{Dazu sagt die Kritik: Das ist eine perfekte Erklärung für liebevolle Zuwendung.}

Sie nahm die Photographie heraus und zerriss sie in zwei Stücke. Draussen vor dem Fenster, aus dem sie die Stücke warf, hatten die Rosen alle ihre Blätter verloren, und von alle den Schmetterlingen, die sonst hier [flogen], war nicht ein einziger zu sehen. (Kōyō, „Shunme no hone“) $)^{55}$

\section{Dazu sagt die Kritik: Er geht vom Niederen und Erdnahen aus und bildet das Hohe und Weite ab.}

Bei Abschied und Empfang der Herren zeigte sich an der Zwischentüre ${ }^{56}$ der mitternächtliche Mond. Weder hat sie jemals den in die Wolken aufsteigenden Kuckuck gehasst, noch hat sie den Ruf der Vögel beklagt. ${ }^{57}$ Um das Geschenk eines Herren in mittleren Jahren an

54 „Fūryū butsu 風流仏“ ([Die elegante Buddha-Figur]): 1889 erschienene Erzählung von Kōda Rohan 幸田露伴 (1867-1947). Die hier zitierte Passage ist im zweiten Abschnitt von Kapitel 10 der Erzählung enthalten (NKiBT 6: 79). Kurz vor der hier zitierten Passage erinnert sich der Protagonist daran, dass die geliebte Frau ihn einst für seine Liebenswürdigkeit gelobt und ihm eine Art von Eheversprechen gegeben hat. Zum Lob zählte die Frau auf, wie der damals kranke Protagonist seine Gastgeberin durch Handreichungen entlastete und fürsorgliche Worte für sie fand, statt über seine Erkrankung zu klagen. Das Eheversprechen bildet den Schluss der Passage.

55 „Kōyō 紅葉“: Schriftstellername des Ozaki Tokutarō 尾崎徳太郎 (1867-1903). Die hier erwähnte Erzählung „Shunme no hone 駿馬骨“ ([Knochen eines edlen Pferdes]) erschien 1889 zunächst in der Zeitschrift Bunko 文庫, im selben Jahr auch in der Sammlung Hatsu shigure 初時雨 (Band 1 der Reihe Shōsetsu gunpō 小説群芳, Tōkyō: Shōseidō 昌盛堂, S. 1-16). Ishibashi zitiert aus „Shunme no hone“ die Schlussszene, in der eine Frau nach langer Zeit in einem Photoalbum das Bild jenes Mannes, dessen Avançen sie einst abgelehnt hatte, wiederfindet. Unmittelbar vor der hier zitierten Passage wird geschildert, dass die Frau ihre Ablehnung nun bereut und zugleich beim Betrachten der Photographie die Phantasie hat, der inzwischen gesellschaftlich hoch aufgestiegene Mann lache sie aus dem Bild spöttisch an und sage, um ihre Reue noch zu steigern, „Nun schau' dir an, was aus mir geworden ist!“ (Ozaki 1889: 9).

56 „Zwischentüre“ für o-jōguchi お錠口: Übergang zwischen dem vorderen, für offizielle Begegnungen und Empfänge gedachten Bereich und dem hinteren, privaten Bereich eines hochherrschaftlichen Hauses.

57 Abgebrochenes Zitat aus der Erzählung „Yanagizakura 柳櫻““ ([Weiden und Kirschen]) von Hirotsu Ryūrō 広津柳浪 (1861-1928). Hirotsu kombiniert mehrere in der klassischen japanischen Lyrik häufig verwendete Topoi und beschreibt damit andeutungsweise Lebensumstände und Stimmung der Protagonistin, einer als Magd in einem reichen Hause dienenden jungen Frau, der nur wenig Zeit für ihr Liebesleben vorbehalten ist. Der „mitternächtliche Mondenschein“ (hier yahan no tsuki 夜半の月, sonst auch yowa no tsuki 夜半の月, 夜はの月) tritt häufig in Verbindung mit „sich hinter Wolken verbergen“ (kumogakure 雲隠れ) auf, so etwa in dem von Murasaki Shikibu stammenden tanka 短歌 (Kurzgedicht) Meguriaite miji ya sore tomo wakanu ma ni kumogakure ni shi yowa no tsukikage めぐりあひてみしやそれともわかぬまに雲隠れにし夜は 
die Zofe $\mathrm{e}^{58}$ legte sie kunstvoll eine Papierschleife ${ }^{59}$ und schrieb darauf ,[Von] Herrn Danjūrō

- Otan'. ${ }^{60}$ In einer Welt, in der es so war. (Ryūrō, Yanagizakura) ${ }^{61}$

の月かげ (Shin kokin wakashū 新古今和歌集 (1201), NKBT 28: 309, Nr. 1497), übersetzt: „Wenn man ihm begegnet, sieht man ihn nicht, oder aber er verschwindet in den Wolken, noch ehe man in erkannt hat, Mond der Mitternacht.“ Das kurze Aufscheinen des Mondes und sein Verschwinden hinter den Wolken evoziert dort Trauer über die Flüchtigkeit der Begegnung der Liebenden. Bei Ozaki überlappt sich das Wolkenmotiv nach Art der „Scharnierwörter“ (kakekotoba) mit dem Motiv des „in die Wolken aufsteigenden Kuckucks“ (kumo ni hairu hototogisu 雲に入る杜鵑). Das darin anklingende Motiv des „Aufsteigens der Vögel in die Wolken“ (kumo ni hairu tori 雲に入る鳥) deutet in der klassischen japanischen Lyrik auf die im Frühling beginnende Rückkehr der Vögel aus ihrem südlichen Winterquartier in den Norden, evoziert also nicht nur den Frühling, sondern auch den Abschied. Das Motiv der Klage über den ersten Schrei der Vögel am anbrechenden Morgen (tori no ne wo kakotsu 鳥の音を託つ), der vom allzu frühen Ende der Liebesnacht kündet, ist beispielsweise ein tanka-Gedicht von Izumi Shikibu 泉式部 (9761030) im von Nijō Tameyo 二条為世 (1250-1338) kompilierten Shoku Senzai wakashū 続千載和 歌集 (Collection of a Thousand Years, Continued, 1318) enthalten. Dort heisst es: Uki hito no / kokoro ni isogu / wakareji wo / yoso naru tori no / ne ni kakotsu ka na うき人の心にいそぐわか れぢをよそなる鳥の音にかこつかな (SKTK 1: 508<Nr. 1344>). „Wie beklagen, ach, die betrübten [Liebenden] doch das Scheiden der Wege, auf das beim Rufe des Vogels sie sich im Herzen einrichten müssen.“ Der „Kuckuck“ (hototogisu 杜鵑) schliesslich deutet nicht nur als Jahreszeitenwort (kigo 季語) auf den Sommer, sondern tritt häufig in Verbindung mit dem (auch bei Ozaki zitierten) Mond auf, der als Erinnerung an eine Liebesnacht im Morgengrauen noch am Himmel steht. Ein Beispiel hierfür ist das folgende, von Fujiwara no Sanesada 藤原実 定 (1139-1191) verfasste Gedicht aus dem von Fujiwara no Toshinari 藤原俊成 (1114-1204) kompilierte Senzai wakashū 千載和歌集 (Collection of a Thousand Years, 1187): Hototogisu nakitsuru kata wo nagamureba tada ariake no tsuki zo nokoreru ほととぎす鳴きつるかたを詠 ればただ有明けの月ぞ残れる (SKTK 1: 188<Nr. 161>). „Nur der Mond war noch übrig im Morgengrauen, als bei des Kuckucks Ruf sie in Gedanken versanken.“ So evoziert auch der Kuckuck die Trauer über die Flüchtigkeit der Begegnung der Liebenden.

58 „Zofe“ für o-tsubone お局.

59 „Papierschleife“ für mizuhiki 水引, papierner Bindfaden für das Verschnüren von Geschenken.

60 Zusammengenommen konnotiert die aus Yanagizakura zitierte Passage, wie abgeklärt (resigniert) die Protagonistin mit der notgedrungen flüchtigen Begegnung mit Männern umgeht, ohne pathetisch-lyrische Klage über ihr Schicksal. Die Zweitverwendung eines eigentlich für eine Frau bestimmten Geschenks als Höflichkeitsgeschenk für ihren Liebhaber betont zusätzlich die pragmatische Haltung der Frau.

61 „Yanagizakura 柳櫻“ ([Weiden und Kirschen], 1889): Erzählung von Hirotsu Ryūrō 広津柳浪 (1861-1928), erstmals erschienen in den Nummern 22, 24 und 26 der Zeitschrift Bunko 文庫 (Juni bis September 1889). Die hier zitierte Passage ist im zweiten Kapitel (Dai-ni shi 第二枝) enthalten. Kurz vor der hier zitierten Passage ist die Rede davon, wie die Protagonistin unter dem Vorwand, die kranken Eltern besuchen zu müssen, Sonderurlaub bekommt. Zu ihren Vergnügungen gehörten das Anschauen von Theateraufführungen und der Umgang mit Männern. (Bunko, Nr. 24, S. 94; Ken'yūsha 1985 [1889]: 9). 
Dazu sagt die Kritik: Ein guter Text, der von der Idee ausgeht und in das Wirkliche übergeht. Er führt nur einen Sprenkel an, lässt aber doch im stillen das ganze Muster mitdenken. ${ }^{62}$

Unter den aufgeführten Schriften gibt es solche, die von der Idee ausgehen und zum Wirklichen übergehen, und solche, die vom Wirklichen ausgehen und in die Idee übergehen. Im Ausgehen und Übergehen gibt es bei ihnen zwar Unterschiede darin, was zuerst kommt und was danach, doch was die Erkenntnis der zentralen Bedeutung des Feilens und des Schmiedens, das Verstehen der feinen Fertigkeit sorgsamer Bestimmung des Gebietes der Poesie angeht, und dass sie letztendlich künstlerische Schriftwerke hervorgebracht haben - darin stimmen sie alle überein. Ach, wie fein sind doch die Hauptpunkte des Feilens und des Schmiedens. Ach, wie trefflich ist doch die Fertigkeit, Idee und Wirkliches aufeinander abzustimmen!

\section{Zusammenfassung der Erörterung}

Vom Beginn meiner Abhandlung über die Idee und das Wirkliche bis hierher bin ich nun beim neunten Abschnitte angelangt. Im ersten habe ich erörtert, was die Poesie sei und was der Poet, im zweiten, was Empfinden, Denken und das Wesen sind, im dritten, was der Charakter der Idee und des Wirklichen ist, im vierten die Unterscheidung der Gebiete des Menschen und der Poesie, im fünften habe ich erörtert, warum die Poesie ewig und unvergänglich sein muss, im sechsten das „Grosse“, ${ }^{3}$ im siebenten den Zusammenhang zwischen Personen und menschlichen Angelegenheiten, im achten habe ich den Kernpunkt des Feilens und des Schmiedens angesprochen und habe ausserdem zur praktischen Erläuterung aus einer grossen Zahl älterer und neuerer Werke exzerpiert. Damit habe ich nun endlich den Punkt erreicht, an dem ich den Hauptteil der Erörterung abschliessen kann. Der ehrenwerte Tan Zong ${ }^{64}$ der Ming-Zeit hat einmal die Makel und Krankheiten der Poesie erörtert und gesagt: „Gefühllos und gewaltsam schreiben; auf den Reim achten und deswegen unmotiviert aufbrausen und stolpern; keine Gestaltung

62 „Im Stillen denken“ für mokkai 默会, ein Ausdruck, den Ishibashi hier wohl von aus dem schon erwähnten Kien shiwa (1771) von Minagawa Kien zitiert.

63 Die Anführungszeichen sind in Ishibashis Originalzitierung enthalten.

64 „Tan Zong“ für Tan Zonggong 譚宗公. Diese Namensvariante des chinesischen Autors Tan Zongji 譚宗輯 (Yuan Chun 元春) und das nachfolgende Zitat entnimmt Ishibashi (wenn auch inakkurat) dem Kien shiwa (1771) von Minagawa Kien. Minagawa gibt dort als Quelle das Jinti qiuyang 近體秋陽 ([Herbstszenen im modernen Stil]) des Tan Zongong an. 
durch Vergleich und Evokation haben. ${ }^{65}$ Das zuvor Aufgetretene und das nachher Aufgetretene gehören nicht zusammen, widersprechen einander, schliessen nicht lückenlos an, haben keine Ordnung“ und so weiter. ${ }^{66}$ Wollen die zahlreichen Poeten, die öffentlich in Erscheinung treten, diese Schwäche vermeiden, so bitte ich sie: Gebt acht auf die Idee und das Wirkliche! Schafft einen harmonischen Ausgleich zwischen der Idee und dem Wirklichen. Es sind wohl nicht wenige Poeten, die seit alten Zeiten die Idee und das Wirkliche erörtern. Doch gibt es so gut wie keinen, der die gegenseitige Bindung von Idee und Wirklichem erörtert, der endlich zu einem Ausgleich der beiden gekommen wäre. Wie ich höre, hatten vor zehn Jahren die beiden Herren Nakamura Masanao und Inoue Tetsujirō einen Disput darüber, ob nun die Idee oder das Wirkliche in der Poesie hochzuschätzen, welches von beiden im Text hochzuschätzen sei. ${ }^{67}$ Es scheint, dass die beiden

65 „Vergleich und Evokation“ für hikyō 比興 (chines. bixing), zwei der sogenannten „Sechs [dichterischen] Prinzipien (wuyi 六義) der chinesischen Gedichtsammlung Shijng 詩経 (ca. 5. Jhdt. v. Chr.): Ausdrücke des Vergleichs (hi) und Ausdrücke, die durch assoziationsgeladene Begriffe Stimmungen evozieren $(k y \bar{o})$.

66 „Makel und Krankheiten der Poesie“ für shi no shibyō 詩の疵病. Minagawas Zitat lautet: Jō naku shite, shiite tsukuri, in wo mite sotsuji shite kore wo tsukuri, funkyō shite shikōshite sue ni tsumazuki, hi kyō no shu nashi, zengo sōzoku sezu, sunawachi ai mujun shi, sōsetsu naku, shidai naku [..] 亡情強作、見韻卒爾為之、奮興而躓末、無比興之趣、前後不相属、輙相 矛盾、無層折、無次第 [..] (Kien-Ikeda 1972 [1771]: 209; die kakikudashi-Fassung folgt der dortigen Bearbeitung durch Ikeda Roshū 池田蘆洲). Ishibashi übergeht in seinem Zweitzitat die Phrase sōsetsu naku 無層折 (,hat keine Gliederung in Abschnitte“).

67 Ishibashi meint eine Diskussion, die Inoue Tetsujirō 井上哲次郎 (1855-1944) und Nakamura Masanao 中村正直 (Keiu 敬宇, 1832-1891) um 1880 zunächst mündlich geführt hatten. Inoue, der soeben sein Studium in der Abteilung Literatur der Tōkyō Universität abgeschlossen hatte, unterbreitete dem renommierten Aufklärer Nakamura, damals an eben jenem Institut Professor für „Chinastudien“ (kangaku 漢学), die Frage der idealen Beschaffenheit von Lyrik und Prosa (shibun 詩文). Auf Nakamuras bereitwillig gegebenen Antworten schliesslich bezieht sich der Beitrag „Nakamura Keiu-ō ni yosete kaku 寄中村敬宇翁書“ ([Geschrieben an den ehrenwerten Nakamura Keiu]), den Inoue in Nr. 19 der Tōyō gakugei zasshi 東洋学芸雑誌 (1883) veröffentlichte. Der Beitrag hat die Form eines in kanbun verfassten respektvollen offenen Briefes. Inoue zitiert darin die Antworten Nakamuras, um gegen sie zu argumentieren. Danach habe Nakamura die Auffassung vertreten, dass in der Literatur allgemein die einfache (kan 簡) Schilderung von Tatsachen (jitsuji 実事) den Vorrang haben müssten, während die üppige (han 繁) Darstellung des Vorgestellten ( $s \bar{z} z \bar{o}$ 想像) allenfalls von sekundärem Wert sei. Inoue vertritt dagegen in seinem Beitrag die Auffassung, dass in der Prosa (bun 文) ein Vorrang der Tatsachen angehen mag, in der Lyrik (shi 詩) hingegen das Vorgestellte vorrangig sein müsse. Aussergewöhnliche Empfindungen und Ereignisse solle man in lyrischen Texten beschreiben und dabei deren realistische Schilderung meiden, weil sie ordinär und auf den Leser ermüdend wirke. Deswegen, so Inoue, nähmen die Dichter des Westens das Vorgestellte in der Lyrik auch so wichtig (wofür Inoue dann zahlreiche Beispiele anführt). Nakamura antwortete auf diese Einlassungen, dass es sowohl für das Üppige und das Leere (kyo 虚) als auch für das Einfache und das Tatsächliche (jitsu 実) in der 
Herren noch nicht aufmerksam auf den Punkt der Harmonisierung von Idee und Wirklichem geworden sind. Ich habe früher einmal das Naniwa miyage gelesen. ${ }^{68}$ Darin ist ein Gespräch des Chikamatsu Monzaemon über Inpon und Kabuki-Theater enthalten, ${ }^{69}$ in dem es heisst: „Es ist erfunden, aber nicht erfunden, es ist wirklich, aber nicht wirklich. Dazwischen liegt die Erbauung. (Aussparung) ${ }^{70}$ Wenn man [jemanden] genauso abbildet wie er im Leben ist, dann mag es eine Prinzessin Yanggui sein, und doch wird es einen Grad erreichen, an dem die Zuneigung vergeht. ${ }^{71}$ Dagegen fassen auch bei den leeren Worten eines Abbildes, ${ }^{72}$ 72 einer gemalten oder in Holz geschnitzten Gestalt, die Menschen am Ende Zuneigung zu ihr, weil man bei aller Übereinstimmung mit der Wirklichkeit die

Literatur je nach Anlass und Zweck einen natürlichen Ort gebe und man keine der beiden Seiten einseitig bevorzugen dürfe. Damit verhalte es sich wie mit dem zwischenmenschlichen Umgang, in dem je nach dem Gegenüber verschiedene Höflichkeitsformen praktiziert werden (Yanagida 1965-1: 408-412; Inoue 1884: 5a-8b). Ishibashi empfindet diesen Abschluss der Diskussion als unbefriedigend, weil trotz der Abgewogenenheit Vorgestelltes und Tatsachen als Antipoden gegeneinanderstehen und nicht miteinander harmonisiert werden.

68 „Naniwa miyage 難波土産 ([Abschiedsgeschenk aus Naniwa], 1738): Hg. Miki Hei'emon Sadanari 三木平衛門貞成 (fl. 1738). Das folgende Zitat stammt aus dem Einleitungsteil (Hottan 発端), eine von Hozumi Ikan 穂積以貫 (1692-1769) verfasste Niederschrift der unter dem (fingierten) Titel „Kyojitsu hiniku ron 虚実皮膜論“ (,Erörterung über das Leere, das Wirkliche und die [sie trennende] Hautschicht“) berühmt gewordenen literaturtheoretischen Überlegungen des jōruri-Puppentheater-Schriftstellers Chikamatsu Monza'emon 近松門左衛門 (16531724). Zitiert wird aus Chikamatsus Entgegnung auf das Argument, dass nur die realistische Darstellung einer Figur vom Publikum angenommen werde. Chikamatsu formuliert hierzu: „Die Kunst ist etwas, das in der Hautschicht zwischen dem Wirklichen und dem Erfundenen liegt.“ (Gei to iu mono wa jitsu to uso to no hiniku no aida ni aru mono nari. 芸というふものは実と虚と の皮膜の間にあるもの也。(NKBT 50: 358) und erläutert exemplarisch, dass die einen Feudalfürsten darstellende Figur nicht zur Erbauung (nagusami) diente, wenn sie so ungeschminkt wie der tatsächliche Feudalfürst auf die Bühne träte. Hier liege die Hautschicht zwischen Wirklichem und Erfundenem. Von hier aus führt Chikamatsu dann die von Ishibashi zitierte These aus. Eine detaillierte Analyse bietet Regelsberger 2004.

69 „Inpon 院本“: das Textbuch eines jōruri-Puppentheaters, hier als Synonym für jōruri-Theaterstück. „Kabuki 歌舞伎“: traditionelle, volkstümliche Theaterform mit lebenden Schauspielern.

70 In der von Ishibashi hier ausdrücklich ausgesparten Passage legt Chikamatsu dar, dass eine allzu realistische und detailfreudige Abbildung eines Menschen in einer Puppe unheimliche Gefühle auslöse und die ursprüngliche Anziehungskraft zerstöre (NKBT 50: 359).

71 „Prinzessin Yanggui“ für Yōki hi 楊貴妃 (chines. Yanggui fei; 727-781), Geliebte des TangKaisers Xuan Zong 玄宗 und Inbegriff der schönen Frau in der klassischen chinesischen Literatur.

72 „Leere Worte des Abbildes“ für esoragoto 画そらごと, hier zur Gegenüberstellung von gegenständlicher Wirklichkeit und der sie abbildenden Kunst. 
Darstellung allgemein hält. Bei der Gestaltung von Motiven ${ }^{73}$ ist es ebenso: Zwar sind sie dem eigentlichen Gegenstand ähnlich, gleichzeitig aber doch allgemein gehalten, und eben das macht sie zur Kunst, ${ }^{74}$ die zur Erbauung unseres Herzens wird. Auch bei den Theatertexten gibt es vieles, bei dem man die Aufmerksamkeit hierauf richten sollte." So sagte Chikamatsu, und weil er damit eigentlich nur ein Detail der Theatertexte und der Maskeraden der Schauspieler erläuterte, kann man es selbstverständlich nicht sogleich auf die Poesie in ihrer Gesamtheit anwenden. Und doch: wenn man reiflich überlegt, worin das besteht, was Chikamatsu eigentlich meint, so stellt sich heraus, dass er von Natur aus mit einem Blick für Ästhetik ausgestattet ist. Er ist einer, der den Unterschied zwischem dem Gebiet des Menschen und dem Gebiet der Poesie begreift. Er ist weder einer, der sich einseitig an die Idee hält, noch ist er einer, der sich einseitig an das Wirkliche hält. Er weiss in der Tat um die Wichtigkeit der Harmonisierung von Idee und Wirklichem. Dass Chikamatsu als Shakespeare Japans bezeichnet wird, ${ }^{75}$ sein Werk bis auf den heutigen Tag unvergänglich und unzerstörbar ist, dass er noch immer unsere literarische Welt hell erleuchtet, ist sicherlich kein Zufall. Jemand sagte zu mir: „Chikamatsu ist in der Tat ein grosser Poet. Saikaku und andere reichen nicht an ihn heran. Chikamatsu ist mit einer Empfindsamkeit ausgestattet, in der er um Klassen erhabener und grösser als Saikaku und andere ist. “76 So hat er geprochen,

73 „Gestaltung von Motiven“ für shukō 趣向, worin „Motiv“ den Handlungsstrang einer Erzählung meint. War zuvor von dem statischen Bild einer Figur die Rede, ist nun von deren Handlung und von dyamischen Prozessen die Rede.

74 „Kunst“ für gei 芸.

75 Tsubouchi Shōyō, der viele seiner Veröffentlichungen den Werken Chikamatsus und Shakespeares gewidmet und immer wieder Vergleiche der beiden unternommen hat, liesse sich zunächst als der Ursprung dieser Apostrophierung vermuten. Allerdings scheint die Einleitung seiner (erst 1909 erschienenen) Abhandlung „Chikamatsu tai Shēkusupia tai Ibusen 近松対 シェークスピア対イブセン“ ([Chikamatsu im Vergleich zu Shakespeare und Ibsen]) eben diese Vermutung zu widerlegen. Es sei, so Tsubouchi dort, in Europa seit etwa dem 18. oder 19. Jahrhundert üblich, einen Dramenautor als den höchstrangigen eines Landes zu kennzeichnen, in dem man ihn als den Shakespeare jenes Landes bezeichnet, etwa nach der Art „Der Shakespeare Frankreichs“ oder „Der Shakespeare Deutschlands“. Was den japanischen Autor Chikamatsu Monzaemon betrifft, so wisse Tsubouchi zwar nicht, wer damit angefangen hat, doch werde jener schon seit langer Zeit der Shakespeare Japans genannt. Das treffe nicht einmal nur auf dessen Rang zu: Chikamatsu sei vielmehr auch in Bezug auf die historische Epoche seines Wirkens, die Lebensumstände, die Besonderheiten als Autor, Inhalt und Form der Werke und anderes Shakespeare ungemein ähnlich. (Tsubouchi 1978 [1909], SYS 10: 769).

76 Wortlaut: Chikamatsu wa jitsu ni dai-shijin nari. Saikaku nado no oyobubeki ni arazu. Chikamatsu wa Saikaku nado yori sūtō kōdai naru kannen wo yūsu 近松八実に大詩人なり、 西鶴などの及ぶべきにあらず、近松八西鶴等より数等高大なる感念を有す. „Saikaku 西鶴“: der bereits erwähnte Ihara Saikaku. In der ursprünglichen Version des „Sō jitsu ron“ (in der Kōko shinbun-Version) verweist Ishibashi deutlich auf den Urheber des Zitats. Es heisst dort 
und es verhält sich wohl auch so. Ich kann mich der Freude darüber nicht erwehren, dass vor zweihundert Jahren jemand lebte, der mir ein wahrer Gleichgesinnter war. $^{77}$

Wer wollte nicht über dessen Leichtfertigkeit lachen, wenn jemand behauptete, im tiefen Tale gebe es keine Orchideen, obwohl er noch nie das tiefe Tal betreten hat, ${ }^{78}$ wenn jemand behauptete, in Kihoku gebe es keine Pferde, obwohl er noch nie durch Kihoku gekommen ist? ${ }^{79}$ Wenn ich mir bei drei oder vier Zeitschriften und Zeitungen anschaue, wie deren Journalisten die heutige Literatur erörtern, so scheint mir das gerade so zu sein wie der Umgang, den eine Stiefmutter mit dem Kind pflegt. Es sind viele, die nach nur flüchtigem Hinschauen unbarmherzig das daran Wertlose attackieren. Sie sagen, die heutige Literatur sei Literatur der Eintagsfliegen. ${ }^{80}$ Sie sagen, die heutige Literatur

zur Einleitung: Ichi nichi Rohan shi to bun wo danzu. Rohan ware ni katatte iwaku一日露伴子 と文を談ず露伴吾に語って曰く、 (,Eines Tages unterhielt ich mich mit Meister Rohan über den Stil. Rohan sagte im Gespräche zu mir“; INZ 3: 144). „Meister Rohan“ meint Kōda Rohan 幸田露伴 (1867-1947), eine stilistisch der Erzählprosa der Edo-Zeit verpflichteter, herausragender literarischer Autor der japanischen Frühmoderne, aus dessen Roman Fūryū butsu Ishibashi weiter oben zitiert hat. Es ist bemerkenswert, dass Ishibashi in seiner (meiner Übersetzung zugrundeliegenden) Koganemura-Version seine Quelle nicht mehr nennt. Im obigen Zitat klingt der Begriff des „Erhabenen“ durch das Wort kōdai 高大 („erhaben und gross“) erneut an. Der wohl von Mori Ōgai in „Bungaku to shizen“ wo yomu 「文学卜自然」 ヨ読ム (Mori 1889b) eingeführte Begriff wird dort gegen das „Schöne“ gesetzt. Gerade durch das Hässliche und die Auflösung der dadurch ausgelösten Konflikte, so Mori, erreichten Erzählungen das Erhabene ( $k \bar{d} d a i$ 高大).

77 „Wahrer Gleichgesinnter“ (shin chiki 真知己) meint hier natürlich Chikamatsu Monzaemon, nicht den Urheber der soeben zitierten Hymne auf denselben.

78 Ishibashi spielt hier auf den Ausdruck yūkoku kajin 幽谷佳人 („die schöne Frau im tiefen Tale“) an. Der Ausdruck bezeichnet das Motiv einer an Felswänden wachsenden Frühlingsorchidee (shunran 春蘭, botan. cymbidium virens), Sinnbild der verborgenen Schönheit.

79 „Kihoku 冀北“ ist der nördliche Teil der chinesischen Provinz Ji zhou 冀州, berühmt für die Zucht ausgezeichneter Pferde. Die implizite Antwort auf Ishibashis rhetorische Frage ist, dass über Schönheit und Qualität der Literatur nicht urteilen kann, wer die beurteilten Texte nicht genau liest und sich keinen Überblick über ihre Umgebung verschafft.

80 „Literatur der Eintagsfliegen“ für fuyū teki no bungaku 蜉蝣的の文学. Ishibashi bezieht sich hier möglicherweise auf „Hihyō ron 批評論“ ([Theorie der Kritik]) von Ōnishi Hajime 大西祝 (1864-1900), erschienen Mai 1888 in Nr. 21 der Zeitschrift Kokumin no tomo (Nachdrucke in NKiBT 57: 75-84 und KBHT 1: 76-83). Das „Hihyō ron“ ist in der Meiji-Zeit die erste schriftliche theoretische Auseinandersetzung mit der Literaturkritik. Ōnishi argumentiert darin, dass Japan literarisch gesehen ein Zwergenstaat sei und zur Entwicklung einer kritikwürdigen Literatur noch viel Zeit brauche. Zurzeit seien die wenigsten der kritisierten Werke überhaupt kritikwürdig. Das Problem der gegenwärtigen Literaturkritik sei, so Ōnishi, dass sie sogar „kleine Heftchen, die, den Eintagsfliegen gleich, am Morgen geboren werden und am Abend sterben“ (asa ni umarete yū ni shi su to iu fuyū ni hitoshiki shōsasshi 朝に生まれて夕に死すといふ蜉蝣に 
enthalte keine gewichtigen Wahrheiten, ${ }^{81}$ sie enthalte kein hohes Denken oder keinen festen, unbeugsamen Charakter. Sie sprechen von vertrauensunwürdigen Kerlen, von Literaten ohne Prinzipien, die zu nichts nutze seien. Sie sagen, jene seien aktiv und umtriebig, aber ohne Lebensgeist, sie besässen kein absolut hohes und kein absolut grosses Denken. Sie besässen keine Gefühle und Empfinden, die dazu angetan sind, den Himmel in Aufruhr und die Erde in Bewegung zu bringen, und so weiter und so weiter. Aber ach, haben jene wohl überhaupt die Substanz, von der Poesie, vom Poeten etwas zu fordern? Fordern sie zuerst etwas, von dem sie dann behaupten, es sei nicht vorhanden? Sind sie solche, die das tiefe Tal betreten und dann in aller Öffentlichkeit erklären, es gebe dort keine Orchideen? Sind sie solche, die durch Kihoku kommen und dann behaupten, es gebe dort keine Pferde ${ }^{82}$ Ich befürchte, dass, wenn man die Geburt solcher Leute in Zeiten etwa von Lessing, Goethe, Schiller, Milton oder Byron $^{83}$ verlegte und ihnen dann die grossartigen Werke dieser grossartigen Poeten vor Augen hielte, sie noch immer Worte wie die zuvor zitierten ausspucken würden, weil sie nicht danach suchen, sondern ihrer Neigung, von

等しき小冊子; NKiBT 57: 79b) aufgreife. Zum „Berufsethos der Kritik“ (hihyō no shokubun 批評 職分) gehöre, dass der Kritiker als avantgardistisch denkender Erzieher (sendōsha 先導者) seinen Auftrag zwar wie ein Aussenstehender (kyokugai sha 局外者), aber mit dem Autor empfindend (dōjō to naru 同情となる) ausüben möge. Der Kritiker möge sich das (implizite oder explizite) Ideal des Autors zueigen machen und auf dessen Grundlage an den dem Kritiker eigenen höchsten Massstäben messen und das Werk kritisieren. Diese höchsten Massstäbe sollten geschult sein an der gegenwärtigen Welt des Denkens (shisō kai 思想界), womit der Philosoph Ōnishi die von der Rezeption europäischer Philosophie geprägte japanische Philosophie der Gegenwart meint (NKiBT 57: 75-84).

81 „Gewichtige Wahrheiten“ für jūdai naru shinri 重大なる真理. Ishibashi bezieht sich hier möglicherweise auf den Text „Shōsetsuka no sekinin 小説家の責任“ ([Die Verantwortung des Romanautors], 1889) von Saganoya Omuro 嵯峨の御室 (Yazaki Shinshirō 矢崎鎮四郎, 1863-1947). Saganoyas Theorie erschien im November 1889 in der Zeitschrift Shigarami zōshi und stellt die Ergründung der Wahrheit (shinri no hakki 真理の発揮) sowie die Erklärung des menschlichen Lebens (jinsei no setsumei 人生の説明) und die Kritik der Gesellschaft (shakai no hihyō 社会の批評) als die Hauptaufgaben des Romanautors dar (KBHT 1: 83). Die Ausrichtung des literarischen Schaffens am Streben nach dem Applaus der Massen sowie nach Ruhm und Reichtum seien zu vermeiden. Saganoya behauptet an keiner Stelle dieses Textes explizit, dass die von ihm postulierte „Wahrheit“ in der gegenwärtigen Literatur nicht existiere, doch Vehemenz und Pathos seines Appells vermitteln diesen Eindruck.

82 Ishibashi bezieht sich auf die weiter oben zitierten Bilder und unterstellt Kritiker-Kollegen, wider besseres Wesen den Wert zeitgenössischer Literatur zu bestreiten.

83 Die Aufzählung der Dichter Gotthold E. Lessing (1729-1781), Johann W. von Goethe (17491832), Friedrich von Schiller (1759-1805), John Milton (1608-1674) und George Byron (1788-1824) deckt die Literaturgeschichte eines Zeitraums von 200 Jahren ab und fällt ausserdem dadurch auf, dass sie im Gegensatz zur ihr vorausgehenden Argumentation nur noch auf europäische, aber nicht mehr auf zuvor erwähnte japanische oder chinesische Autoren Bezug nimmt. 
vorneherein in Bausch und Bogen zu sagen „Da ist nichts, da ist nichts!“ folgen. Ich will damit zwar nicht eindeutig behaupten, es gebe in unserer Zeit einen Goethe oder einen Milton, ${ }^{84}$ aber da eine Zeit dazu angetan ist, grosse Persönlichkeiten erwachsen zu lassen, mag es wohl sein, dass jemand, der ein Milton oder ein Goethe werden könnte, irgendwo verborgen ist. Es ist nicht meine Art, ungeachtet dieser Tatsache darüber kalt und unbewegt hinwegzusehen und die Literatur unserer Tage wie einen Feind zu behandeln. Ich bin der Überzeugung, dass es kein kluges Vorgehen ist, derart nutzlos mit dem Pinsel zu spielen und die gegenwärtige Literatur kalt abzuweisen. Man möge lieber mit einem verständigen Blick für die Poesie die Poetik erörtern, möge sie lieben, möge zu ihrer Weiterentwicklung beitragen und sie führen. ${ }^{85} \mathrm{Ach}$, wie sollte angesichts dieser dringenden Notwendigkeit meine Erörterung der Idee, des Wirklichen ${ }^{86}$ nichts als dilettantische Liebhaberei sein?

\subsection{Nachwort des Übersetzers: Verdienste des „Sō jitsu ron“}

Die grösste literaturtheoretische Leistung des Sō jitsu ron besteht im Entwurf eines Konzeptes „Poesie“ (shi 詩), das sich vom Konzept „Literatur“ (bungaku 文学) deutlich unterscheidet. Ein Vergleich mit dem Mainstream der

84 Die intertextuelle Verflechtung dieser Passage ist zumindest dreischichtig. Ishibashi bezieht sich hier (an der Kombination „Goethe-Milton“ erkennbar) auf den Artikel „Shimada Saburō ni shissu 島田三郎に質す“ ([Was ich Shimada Saburō vorwerfe]), den Uchida Fuchian 内田不知庵 (1868-1929) am 2. Feb. 1890 in der Kokumin shinbun veröffentlichte und dem Ishibashi im Grossen und Ganzen zustimmt (KBHT 1: 94). Uchida seinerseits hatte mit seinem Artikel auf einen unter dem Titel „Bungaku gokusui 文学極衰“ ([Extremer Verfall der Literatur]) in Nummer 191 (Dez. 1889; KBHT 1: 89) veröffentlichten Artikel geantwortet. Der anonyme Verfasser jenes Artikels wiederum zitiert und unterstützt die vom als Gesellschaftskritiker und Christ profilierten Zeitungsmacher Shimada Saburō 島田三郎 (1852-1923) angeblich während einer Beiträgerversammlung der Jogaku zasshi mündlich vorgetragene Klage, die Gegenwart sei eine Epoche des extremen Verfalls der Literatur. Uchida sieht zwar im gegenwärtigen Japan seinerseits keine Poeten vom Range eines Goethe oder eines Milton, urteilt aber im Übrigen wesentlich milder als der anonyme Verfasser des erwähnten Artikels. Ishibashi wiederum mildert hier das schon von Uchida abgemilderte Urteil weiter ab, in dem er die Möglichkeit zulässt, dass japanische Dichter vom Range eines Goethe oder eines Milton im Verborgenen existieren und nur ihrer womöglich durch Literaturkritiker zu leistenden Entdeckung harren.

85 Das Bild von der unterentwickelten japanischen Literatur der Gegenwart und die Idealvorstellung von einem die Autoren und das Publikum liebevoll erziehenden Literaturkritiker weist deutlich eine Anlehnung an das „Hihyō ron“ des Ōnishi Hajime auf.

86 Wie schon bemerkt, zitiert Ishibashi hier den Titel seiner Abhandlung in einer formalen Variante: $\bar{A}$, gojin ga sō, jitsu ron wo sō suru ani kōzu naran ya ア、吾人が想、実を州する豈 に好事ならんや, worin die Begriffe sō und jitsu durch ein Komma getrennt werden. 
Literaturgeschichtsschreibung macht das deutlich. Suzuki/Tyler 2006 thematisiert zwar die Geschichte des japanischen Konzeptes „Literatur“, konzentriert sich dabei aber auf die Wörter bungaku, bi bungaku 美文学 („schöne Literatur“), jun bungaku 純文学 („reine Literatur“) und bungei 文芸 („literarische Kunst“). Dem wandelndenen Begriffsinhalt des Wortes bungaku folgend, zeichnet Suzuki/Tyler 2006 die Loslösung der Textkunst aus dem mit bungaku ursprünglich assoziierten Feld der Gelehrsamkeit nach. Ein Konzept, das als Oberbegriff nicht bungaku, sondern shi hat, wäre der historisch-linearen Darstellung wohl im Wege gewesen. So verwundert nicht, dass Suzuki/Tyler 2006 auf Ishibashis Literaturkonzept nicht eingeht. $^{87}$

Bemerkenswert ist im „Sō jitsu ron“ an sich schon die in der Einleitung vorgenommene Integration aller dort erwähnten Textsorten der „westlichen“ und der japanischen Literatur. Denn diese stellt dem Konzept einer japanischen Nationalliteratur das Konzept einer „Weltliteratur“ mit einem japanischen Bestandteil gegenüber.

Doch der Entwurf des Konzeptes „Poesie“ im „Sō jitsu ron“ beschränkt sich nicht auf eine abstrakte, rein begriffliche Integration aller Literaturen. Vielmehr stellen die intertextuellen Bezüge, die das „Sō jitsu ron“ insgesamt wie ein dichtes Netz überziehen, konkrete literarische Prototexte aus Japan mit solchen aus China, Deutschland, England, Russland und Norwegen auf eine Stufe. Nun mag man einwenden, dass ein durch intertextuelle Bezüge praktisch umgesetztes Konzept „Weltliteratur“ im Prinzip schon Tsubouchi Shōyō in „Shōsetsu shinzui“ (1885/6) präsentiert habe, etwa, wenn er als Beispiel für die Textsorte „Fabel“ in einem Atemzug die griechischen Fabeln des Aisopos (Aesop; Mythōn synagōgē, 6. Jhdt. a. Chr.) und das dem Chinesen Zhuang Zhou 荘周 (ca. 365-290 a.Chr.) zugeschriebene Zhuangzi 荘子 (Zhuangzi) nennt. ${ }^{88}$ Dem wäre aber zu entgegnen, dass Tsubouchi zum einen (fast) nur die Erzählprosa behandelt, zum anderen für den Beleg seiner Thesen fast ausschliesslich auf japanische literarische Prototexte zurückgreift.

Im „Sō jitsu ron“ gelingt es Ishibashi, die schaffenstheoretischen Gedanken des konfuzianischen Gelehrten Minagawa Kien (1735-1807) mit Grundzügen des von Lessing und den grossen Theoretikern der Goethe-Zeit geprägten literaturästhetischen Diskurses zu verbinden. Diesen hat Ishibashi in Auszügen zwar auch im Original studiert, doch stützt sich er sich hauptsächlich auf die Deutsche Poetik (1879), in der Werner Hahn in den Kapiteln II („Schönheit“) und III („Poesie“)

87 Erwähnung findet Ishibashi lediglich als Literaturkritiker und mit seiner im „Sō jitsu ron“ enthaltenen Forderung nach „grosser spiritueller Präsenz“ (,great spiritual presence“) beim Verfassen von Literatur (Suzuki/Tyler 2006: 171-172; 180). Welches Wort aus dem Original dabei mit ,great spiritual presence“ übersetzt wurde, ist allerdings nicht zu erfahren.

88 NKiBT 3: 55; Tsubouchi/Twine 1981: 14. 
Kerngedanken aus der Diskussion zusammengetragen hat. Die Einfachheit, in der Hahn dies tat, machte es Ishibashi überhaupt erst möglich, die erwähnte Verbindung zur Theorie des japanischen konfuzianischen Gelehrten Minagawa Kien, der zwar in etwa gleichzeitig, aber ohne jede Verbindung zu Lessing wirkte, herzustellen. Gleichwohl ist die aus dieser Einfachheit entwickelte Literaturtheorie weder unspezifisch noch primitiv. Und die Verbindung eröffnet die Möglichkeit, neben der japanischen Literatur auch ihre Theorie von einengenden nationalen Zusammenhängen $\mathrm{zu}$ befreien. Nähme man das „Sō jitsu ron“ als Ausgangspunkt einer modernen japanischen Literaturtheorie, müsste der von Hijiya-Kirschnereit (1979) konstatierte Stand der japanischen Literaturtheorie der 1970er Jahre als Ergebnis eines Rückschrittes betrachtet werden.

\section{Abkürzungen}

\section{Sigle Auflösung}

INZ Ishibashi Ningetsu zenshū 石橋忍月全集. Hgg. Yamamoto, Kenkichi 山本健吉, Inagaki, Tatsurō 稲垣達郎 und Odagiri, Susumu 小田切進. 4 Bde. Tōkyō: Yagi shoten 八木書店. 1995-1996.

KBHT Kindai bungaku hyōron taikei 近代文学評論大系. Tōkyō: Kadokawa shoten 角川書店.10 Bde. 1971-1975.

KNBT Kindai nihon bungaku taikei 近代日本文学大系. 25 Bde. Tōkyō: Kokumin tosho 国民図 書, 1926-1928.

KnT Kokumin no tomo 国民之友. Nr. 1-372 (1887-1889). Faksimile Tōkyō: Meiji bunken 明 治文献, 1966-1968. Hg. Ritsumeikan Daigaku jinbun kagaku kenkyūjo Meiji Taishō shi kenkyū kai 立命館大学人文科学研究所明治大正史研究会

MBgZ Meiji bungaku zenshū 明治文学全集. 99 Bde. + Suppl. Tōkyō: Chikuma shobō 筑摩書 房, 1966-1989.

NKBT Nihon koten bungaku taikei 日本古典文学大系. 100 Bde. + Supp. und Indices. Tōkyō: Iwanami shoten 岩波書店, 1958-1968.

NKBZ Nihon koten bungaku zenshū 日本古典文学全集. 53 Bde. Tōkyō: Shōgakukan 小学館, 1973-1976.

NKiBT Nihon kindai bungaku taikei 日本近代文学大系. 61 Bde. Tōkyō: Kadokawa shoten 角川 書店, 1970-1975.

NMZ Nihon meicho zenshū 日本名著全集: Edo bungei no bu 江戸文芸之部. 31 Bde. Tōkyō: Nihon meicho zenshū kankōkai 日本名著全集刊行会, 1926-1929.

OGZ Ōgai zenshū 鴎外全集. 33 Bde. + 2 Suppl. Tōkyō: Iwanami shoten 岩波書店, 1951-1956.

SKTK Shinpen Kokka Taikan 新編国歌大観. 10 Bde. Tōkyō: Kadokawa shoten 角川書店, 1983-1992.

ZKKTS Zoku Kokuyaku kanbun taisei 続国訳漢文大成: Bungaku bu 続文学部. Hg. Kokumin Bunko kankōkai 国民文庫刊行会. 50 Bde. Tōkyō: Kokumin Bunko kankōkai 国民文庫刊 行会, 1928-1958. 
Kleine systematische Inkonsistenzen im „Sō jitsu ron“ sind zwar nicht zu leugnen, ${ }^{89}$ doch dürfen wir den Text in seiner Gesamtheit getrost als einen wichtigen Schritt auf dem Weg zu einer wissenschaftlichen theoretischen Auseinandersetzung Japans mit seiner Literatur betrachten. Die wirkungsgeschichtliche Einordnung bleibt allerdings künftigen Arbeiten vorbehalten.

\section{Literaturverzeichnis}

\section{Primärliteratur}

[Anonymus] (1968) [10. Jhdt.]: Ise monogatari 伊勢物語. Moderner Nachdruck: NKBT 9: 81-204. [Anonymus] (1972) [1889]: „Bungaku gokusui 文学極衰“. In: Jogaku zasshi 191 (Dez. 1889). Moderner Nachdruck: KBHT 1: 89.

Ejima, Kiseki 江島其磧 (1928-1929) [1732]: Keisei uta shamisen けいせい歌三味線. Moderner Nachdruck: KiNBT 5: 417-519.

Gao, Qi 高啓 / Kubo, Tenzui 久保天髄 (1930) [1374]: Kō Seikyū shishū 高青邱詩集 [Gao Qingqiu shiji 高青邱詩集]. Moderner Nachdruck: ZKKTS 3: 19-22.

Gerok, Karl (1885): Der letzte Strauß: vermischte Gedichte: Der ,Blumen und Sterne“ neue Folge. Stuttgart: Greiner \& Pfeiffer.

Hahn, Werner (1879): Deutsche Poetik. Berlin: Hertz.

Hirotsu, Ryūrō 広津柳浪 (1889): „Yanagizakura 柳櫻“. In: Bunko 文庫 22, 24, $26: 1$.

Hirotsu, Ryūrō 広津柳浪 (1985) [1889]: „Yanagizakura 柳櫻“. In: Ken’yūsha kei zasshi shūsei 硯 友社系雑誌集成. Hrsg, von Ken'yūsha 硯友社. Tōkyō 東京: Yumani shobō ゆまに書房 7 (Zasshi sōsho 雑誌叢書): 9.

Ichi Daigakusei 一大学生 (1889): „Shigarami zōshi no niki しがらみ草紙の二奇“. In: Yomiuri shinbun 読売新聞, 31. 10.1889:2.

Ihara, Saikaku 井原西鶴 (1926-1929) [1693]: Saikaku okimiyage 西鶴置土産. Moderner Nachdruck: NMZ 2: 651-726.

Ihara, Saikaku 井原西鶴 (1969) [1668]: Kōshoku gonin onna 好色五人女. Moderner Nachdruck: NKBT 47: 217-321.

Inoue, Tetsujirō 井上哲次郎 (1884): Sonken shishō 巽軒詩鈔. 2 Bde. Tōkyō 東京: Sakagami Hanshichi 阪上半七.

Ishibashi, Ningetsu 石橋忍月 (1995-1996) [1889]: „Bungaku hyōron Shigarami zōshi 文学評論 柵草州紙“. In: Kokumin no tomo 国民之友 67. Moderner Nachdruck: INZ 3: 95-96.

Ki no Tomonori 紀友則 et al. (1958) [914]: Kokin waka shū 古今和歌集. Moderner Nachdruck: NKBT 8.

Kōda, Rohan 幸田露伴 (1974) [1889]: Fūryū butsu 風流仏. Moderner Nachdruck: NKiBT 6: 37-86.

89 So gibt es etwa inhaltliche Überlappungen zwischen den einzelnen Abschnitten. Das aus seiner Sicht ideale Verhältnis von „Idee“ und „Wirklichem“ im literarischen Text demonstriert Ishibashi anhand zahlreicher Beispiele, an einigen Stellen versäumt er aber die sachliche Begründung für sein Lob (so etwa bei seinem Kommentar zu einer Passage aus dem Fūryū butsu von Kōda Rohan). 
Matsuo, Bashō 松尾芭蕉 (1970) [1687]: Nozarashi kikō 野ざらし紀行. Moderner Nachdruck: NKBT 46: 35-44.

Miki, Heiemon Sadanari 三木平衛門貞成 / Hozumi, Ikan 穂積以貫 (1944) [1738]: „Jōruri monku hyōchū Naniwa miyage 浄瑠璃文句評註難波土産: Hottan 発端“. In: Nihon engeki bunken kenkyū kai 日本演劇文献研究会 (Hg.): Jōruri kenkyū bunken shūsei 浄瑠璃研究文献集成. Tōkyō 東京: Hokkō shobō 北光書房: 68-74.

Minagawa, Kien 皆川淇園 (1972) [1771]: „Kien shiwa 淇園詩話“. In: Nihon shiwa sōsho 日本詩 話叢書 5. Hrsg. von Ikeda, Roshū 池田蘆洲und Kokubu, Takatane 国分高胤 (2. Aufl). Tōkyō 東京: Ōtori shuppan 鳳出版: 177-226.

Mori, Ōgai 森鴎外 (1889a): „Shigaramizōshi no honryō wo ronzu 柵草紙の本領を論ず“. In: Shigaramizōshi 柵草紙, 1: 1-4; Moderner Nachdruck: OGZ 16: 25-28.

Mori, Ōgai 森鴎外 (1889b): ,,Bungaku to shizen“ wo yomu 「文学卜自然」Э読么“. In: Kokumin no tomo 国民之友 4 (50 (Mai 1889): 18. Moderner Nachdruck: OGZ 16: 11-19.

Mori, Ōgai 森鴎外 (1889c): „Futatabi geki wo ronjite yo no hyōka ni kotau 再び劇を論じて世の 評家に答ぶ“. In: Shigarami zōshi しがらみ草紙 3 (Dez. 1889). Moderner Nachdruck: OGZ 16: $35-60$.

Mori, Ōgai 森鴎外 (1953) [1889d]: „Shigarami zōshi to geki to 柵草紙と劇と“. In: Yomiuri shinbun, Nov. 1889. Moderner Nachdruck: OGZ 16: 61-62.

Murakami, Kō 村上剛 (1989) [1852]: Bussandō shishō 仏山堂詩鈔. Moderner Nachdruck: Nihon kanshi 日本漢詩 15 (Shishū 詩集; Hg. Fujikawa, Hideo 富士川英郎; Tōkyō 東京: Kyūko shoin 汲古書院): 409-578.

Nakamura, Masanao 中村正直 (1883): Futatabi Inoue Sonken kun ni sho su 復井上巽軒君書. In: Tōyō gakugei zasshi 東洋學藝雜誌 19: 512-514.

Ōnishi, Hajime 大西祝 (1888): „Hihyō ron 批評論“. In: Kokumin no tomo 国民之友 2 (21. Apr.): 25. Moderner Nachdruck: KBHT 1: 76-83.

Ozaki, Kōyō 尾崎紅葉 (1889): „Shunme no hone 駿馬骨“. In: ders.: Hatsu shigure 初時雨. Tōkyō 東京: Shōseidō 昌盛堂; Shōsetsu gunpō 小説群芳 1: 1-16.

Saganoya, Omuro 嵯峨の屋御室 (1889): „Shōsetsu ka no sekinin 小説家の責任“. In: Shigarami zōshi しがらみ草紙 (2 (November 1889)). Moderner Nachdruck: KBHT 1: 83-85.

Scheffel, Victor von (1870) [1854]: Der Trompeter von Säkkingen: Ein Gesang vom Oberrhein. Stuttgart: J.B. Metzlersche Verlagsbuchhandlung.

Sei, Shōnagon 清少納言 (1969) [1000]: Makura no sōshi 枕草子. Moderner Nachdruck: NKBT 19: 5-402.

Shinseisha 新声社 (1971 [1889]: Omokage 於母影. In: Nihon kindai bungaku taikei 日本近代文 学大系, Bd. 52 (Meiji Taishō shishū 明治大正訳詩集; hg. Yoshida, Sei’ichi 吉田精一; Tōkyō: Kadokawa shoten 角川書店): 105-167.

Tsubouchi, Shōyō 坪内逍遥 (1977-1978) [1909]: „Chikamatsu tai Shēkusupia tai Ibusen 近松対 シェークスピア対イブセン“. In: ders.: Shōyō senshū 幍遥選集 10 (Muraguchi, Kazuo 村口 一雄, Hg.); Tōkyō 東京: Daiichi shobō 第一書房: 769-813.

Uchida, Roan 内田魯庵 (1972) [1890]: „Shimada Saburō ni shissu 島田三郎に質す: Zengō ni tsuzuku 前号につづく“. In: Kokumin shinbun 国民新聞, Jan./Feb. 1890. Moderner Nachdruck: NKiBT 57: 94.

Wang, Wei 王維 / Chen, Tiemin 陳鐵民 (1997) [759]: Wang Wei ji jiaozhu 王維集校注. 4 Bde. Beijing 北京: Zhonghua shuju 中華書局 (Zhongguo gudian wenxue jiben congshu 中國古 典文學基本叢書). 


\section{Sekundärliteratur}

Chiba, Shinrō 千葉眞郎 (2006): Ishibashi Ningetsu kenkyū 石橋忍月研究: Hyōden to kōshō 評 伝と考証. Tōkyō: Yagi shoten 八木書店.

Ihara, Saikaku 井原西鶴 / De Bary, William Theodore (1956) [1686]: Five Women Who Loved Love: Amorous tales from 17th-centry Japan [Kōshoku gonin onna]. Tōkyō 東京: C.E. Tuttle. Ihara, Saikaku 井原西鶴 / Leutner, Robert (1975) [1693]: “Saikaku’s Parting Gift: Translations from Saikaku Okimiyage”. In: Monumenta Nipponica (Vol. 30, No. 4, Winter, 1975): 357-391.

Ki no Tomonori 紀友則 et al. (1985) [914]: Kokin Wakashū: The First Imperial Anthology of Japanese Poetry. Transl. McCullough, Helen. Stanford (Calif.): Stanford University Press.

Naumann, Wolfram / Naumann, Nelly (1973): Die Zauberschale: Erzählungen vom Leben japanischer Damen, Mönche, Herren und Knechte. München: Hanser.

Regelsberger, Andreas (2004): „Theater an der hauchdünnen Grenze zwischen Wahrheit und Schein: Betrachtungen zur Ästhetik des Jōruri aus dem Naniwa miyage (1738)“. In: Sünden des Worts. Festschrift für Roland Schneider zum 65. Geburtstag. Hrsg. von Árokay, Judit und Vollmer, Klaus. Hamburg: Gesellschaft für Natur- und Völkerkunde Ostasiens: Mitteilungen der Gesellschaft für Natur- und Völkerkunde Ostasiens e.V. Hamburg, 141: 79-108.

Sei, Shōnagon 清少納言 / Arnold-Kanamori, Horst (2001) [1000]: Klassisches Japanisch: 5., Makuranosōshi: 2. Die „Kopfkissenhefte“ der Sei Shōnagon: Aufzeichnungen einer japanischen Hofdame um das Jahr 1000. Hamburg: Kovac.

Suzuki, Sadami 鈴木貞美 / Tyler, Royall (2006): The Concept of “Literature" in Japan. 1. English ed. Kyōto 京都: International Research Center for Japanese Studies (Nichibunken monograph series, 8).

Tao, Yuanming 陶淵明 / Chang, Lily Pao-Hu (1954) [427]: The Poems of T'ao Ch'ien. 2. Aufl. Honolulu: University of Hawai'i Press.

Tsubouchi, Shōyō 坪内逍遥 / Twine, Nanette (1981): The Essence of the Novel: Tsubouchi Shōyō. Queensland: University of Queensland Press (Occasional Papers, 11).

Yanagida, Izumi 柳田泉 (1965): Meiji shoki no bungaku shisō 明治初期の文学思想. 2 Bde. Tōkyō 東京: Shunjū sha 春秋社.

Anmerkung: $\mathrm{Zu}$ den verschiedenen Textfassungen und der Grundlage der hier gegebenen Übersetzung siehe Teil I in Asiatische Studien/Études Asiatiques 71.1. 